DOI 10. 18307/2019. 0514

(C) 2019 by Journal of Lake Sciences

\title{
湖泊沉积物一水界面研究进展与展望”
}

\author{
范成新 \\ (中国科学院南京地理与湖泊研究所湖泊与环境国家重点实验室,南京 210008)
}

\begin{abstract}
摘 要: 湖泊沉积物一水界面是以水层/沉积层物相为基础、具有一定立体尺度的交接面,界面上所发生的由生物积极参 与的物理、化学和生物学微小反应和微环境变化, 都会对界面附近物质的状态和迁移转化行为产生着复杂影响. 本文首 先回顾了沉积物一水界面研究 100 多年来的发展历程及国内外近 20 年发展. 然后系统介绍了国际上对沉积物一水界面的 物理尺度与结构的宏观和微观认识; 重点综述了沉积物间隙水的取样、物化性质的多维测定与结构表征、过程的静态和 动态模拟等湖泊沉积物一水界面研究技术与方法; 分析和展示了氮磷等营养物、重金属和持久性有机污染物在湖泊沉积 物一水界面迁移转化过程的研究进展; 总结和归纳了在沉积物一水界面过程的模型研究、沉积物一水界面物质交换的定量 化、界面过程与湖泊生态环境灾害关系等模型与过程效应方面的研究成果. 最后对沉积物一水界面信息获取技术的研发 方向、界面物质交换定量化研究的关注点,以及加强模型的应用和构建等方面进行了展望.
\end{abstract}

关键词: 沉积物一水界面;间隙水取样;营养盐;动态模拟;通量估算; 扩散;模型

\section{Advances and prospect in sediment-water interface of lakes:A review}

\section{FAN Chengxin}

( State Key Laboratory of Lake Sciences and Environment, Nanjing Institute of Geography and Limnology, Chinese Academy of Sciences, Nanjing 210008, P.R.China)

Abstract: The sediment-water interface in freshwater lakes is a three-dimensional interface based on the water/sediment facies. The micro-reactions, which are actively participated by organisms, and micro-environmental changes of physical, chemical and biological reactions on the interface will have a complex impact on the state and migration-transformation behavior of substances near the interface. In this paper, the courses of sediment-water interface research in the past 100 years, especially the development in the recent 20 years, both at home and abroad are reviewed from a comprehensive perspective. Firstly, the international macro- and micro- understanding of the physical scale and structure of sediment-water interface is introduced. The techniques and methods applied in the aquatic sediment-water interface research and practice, which are the sampling of interstitial water, multi-dimensional measurement of physicochemical properties in sediments and their structure characterization, static/dynamic processes simulation and others are selected for detailed analysis. Moreover, the advances on the migration and transformation process of phosphorus and nitrogen and other nutrients, heavy metals and persistent organic pollutants in aquatic sediment-water interface are discussed, especially in respects of modelling study of sediment-water interface process, quantification of substance exchange across the sedimentwater interface, and relationships between the interface processes and lake eco-environmental disasters. Finally, the development trend for the future research of information acquisition technology for sediment-water interface analysis, the focus of quantitative research on interfacial substance exchange, and the application and construction of more efficient models etc. are favorably suggested. Keywords: Sediment-water interface; interstitial water sampling; nutrient; dynamic simulation; flux estimation; diffusion; model

湖泊是内陆水体相对封闭的一类地貌单元, 它收集了来自流域内一切可由水力搬运和大气沉降来的碎 屑和颗粒填充物, 以及湖体内可能形成的化学沉积和生物沉积物 ${ }^{[1-2]}$. 受湖盆形态、地貌的支配和对上覆湖 水体的承接, 沉积物成为湖泊中与水体接触最广泛的一类固相介质. 在最大可覆盖整个湖底面积的沉积物

* 国家水体污染控制与治理科技重大专项 (2012ZX07103-005) 资助. 2019-08-15 收稿;2019-08-18 收修改稿. 范成 新(1954 ), 男,研究员;E-mail:cxfan@ niglas.ac.cn. 
与上覆水体交接区, 构成了宏观意义上的沉积物一水界面 ( sediment-water interface, SWI $)^{[3-4]}$. 据维基百科 (Wikipedia) 词典, 沉积物一水界面是沉积物相与上覆水相之间的边界层. 在沉积物一水界面之上是化学性质 相对均匀的水层, 界面 (或近表层沉积物) 之下为物理结构相对稳定的沉积层, 因此一般将沉积物一水界面 定义为具有一定厚度与复杂结构的区层 ${ }^{[5]}$, 即两相之间没有明显的分界线. 界面附近的沉积物不仅仅是湖 泊系统中的固相介质, 更重要的是在其形成期, 通过吸附、包夹、容纳和着生等作用, 会累积湖盆中大部分种 类和数量污染物 ${ }^{[6]}$. 表层沉积物中的污染物大多呈活性或未完全降解状态, 因此极易参加沉积物内部和在 沉积物一水界面间的迁移转化和物质交换作用, 使得沉积物一水界面成为湖泊中物质迁移转化过程发生的 主要场所 ${ }^{[7]}$. 然而在湖泊底部, 包括温度、溶解氧、物理扰动和生物种群数量等在内的环境条件往往不断变 化, 通过热力学和 (生化) 动力学控制下的氧化一还原、吸附一解析、降解一化合等作用, 以极其复杂的方式影 响着沉积物一水界面附近物质的迁移转化行为 ${ }^{[8]}$.

沉积物一水界面是陆地表层系统最重要的界面之一,在湖泊中, 几乎所有环境污染和生态风险问题等都 与沉积物一水界面过程或效应有关, 因此对界面上物质流过程的研究, 被认为是深人和系统了解水生态系统 变化、乃至结构与功能响应的切人点之一 ${ }^{[7-11]}$. 为更好地研究沉积物一水界面的基础理论问题, 解决当今湖 泊中的富营养化和有毒有害风险等实际生态环境问题, 本文将通过回顾沉积物一水界面的研究历程, 总结当 今的研究动态和热点, 结合介绍新方法、新技术和理论模型, 重点对湖泊沉积物一水界面近 20 年来主要成果 进行系统梳理和总结, 为读者提供专业性和涉足阶段的知识储备参考.

\section{1 沉积物一水界面研究历程及国内外近 20 年发展}

自 1915 年 Carruthers 在苏格兰中央山谷石炭纪沉积物调查中, 提出沉积物与水可通过面进行相互作 用 ${ }^{[12]}$ 的概念起, 直到 1941 年 Mortimer 公开发表的湖泊泥水间 (between mud and water) 可溶性铁磷物质交换 研究 ${ }^{[13]}$ 这一人类首篇关于湖泊沉积物一水界面研究的科技文献, 已整整过去了 26 年. 经过短暂期的泥一水 界面 ( mud-water interface) 非专业词语的使用 ${ }^{[14]}, 1958$ 年美国 Goldberg 博士成为在公开发表的文献中首个 采用了英文“沉积物一水界面 ( sediment-water interface)” 这一词语的学者 ${ }^{[15]}$, 此后逐步推广并被同行接受为 专业术语 ${ }^{[4,16]}$. 据对 ScienceDirect 文献数据库自 1880 年来的检索, 从首篇文献 ${ }^{[13]}$ 出现的近 80 年间, 关于沉 积物一水界面外文出版的文献数大致呈现出 3 个阶段 (图 1): 1940-1965 年为探索期, 文献零星出现, 反映 研究者们在开拓该领域时可能面临着知识、手段储备不足、缺乏交流等问题,基本是运用化学地理学或地质 学知识孤立地进行现象的解释 ${ }^{[13-15,17]} ; 1965-1975$ 年为稳定期, 平均每年约产出 4 篇文献, 并已引人了环境 或污染的概念, 反映沉积物一水界面的研究已在领域上有了拓展, 并初步有了研究群; 1976 年以来为增长 期, 文献呈线性快速增加, 研究领域逐步扩大, 研究方法和手段越来越多样, 研究的国家和机构也大量增加. 其中 1974 年 11 月在法国 Les Arcs 召开的“The Benthic Boundary Layer” 会议为这一阶段成果的增加起到了 巨大的推动作用. 在这次学术讨论会上, 来自美国、英国、加拿大、荷兰和德国等国家的沉积物一水界面领域 科学家交流了各自国家和机构在水底沉积物及界面所取得的物理、化学、生物学、地质学和工程学方面的成 果, 会后组织成立了 6 个工作组, 汇总出版了专著 ${ }^{[16]}$. 这次学术会议及其系统成果为沉积物一水界面后期研 究的多领域发展和成果产出指明了努力方向. 对 1976-2018 年间的文献统计显示, 平均每年发表沉积物一 水界面研究的外文文献 57.3 篇,其中 2018 年发表的外文文献已达 142 篇.

我国对沉积物一水界面的研究起步较晚, 实质性研究大约起自 1980s 中期. 中国科学院地球化学研究所 万国江先生根据 1983 年 9 月参加在瑞士召开的 “湖泊化学过程学术研讨会”, 以学术简报的形式介绍了国 外学者在 “湖泊环境中微粒和水、沉积物和水之间的相互作用” 最新研究成果 ${ }^{[18]}$, 并首次采用了湖泊 “沉积 物一水界面”这一中文术语. 1987 年厦门大学洪家珍等公开发表了我国迄今最早一篇有关 “沉积物一水界 面” 的研究性文章, 关于界面附近硅酸盐、水合氧化物和 $\mathrm{FeS}$ 沉淀对二价锰的氧化影响 ${ }^{[19]}$; 紧接着吴德殊等 发表了我国第 1 篇关于湖泊沉积物一水界面的文章, 介绍了沉积物一水界面采样装置的研制 ${ }^{[20]}$. 这两篇文献 开创了我国海洋和湖泊沉积物一水界面研究的先河. 对阶段的划分发现, 我国的沉积物一水界面研究只经历 了稳定期和增长期两个阶段 (图 1). 1984-1994 年为初创后的稳定期, 主要是借鉴国外的研究方法和成果, 针对我国自身的水环境问题, 探索和开展以物质交换为主的沉积物一水界面的研究; 1995 年至今为增长阶 


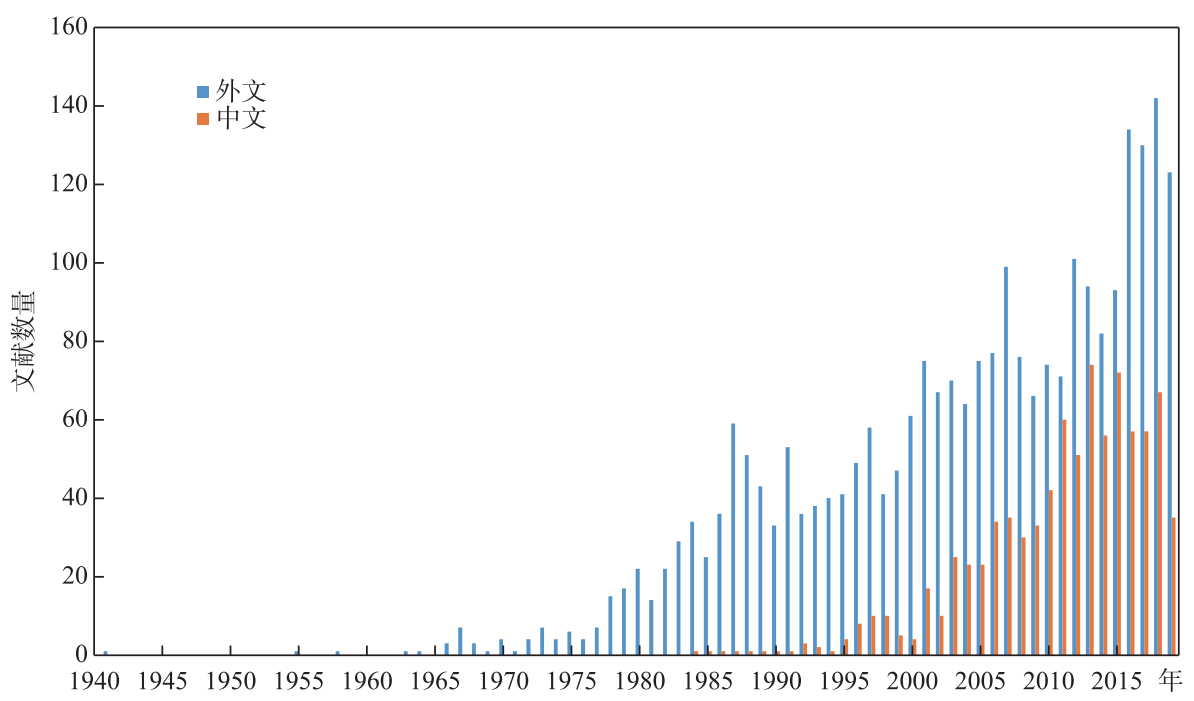

图 1 有关 “沉积物一水界面” 研究正式发表的中外文献数量统计 (2019 年为 1-6月的数据)

Fig.1 Quantitative statistics of domestic and foreign literatures on the study of “sediment-water interface”

段, 中文发表的文献数与外文的文献数同步上升. 实际近 10 多年来, 中国学者每年除发表数十篇中文主题 文献外,对外文“sediment-water interface,SWI” 文献的贡献也呈较大幅度地增加. 据对 2018 年发表的 143 篇 SWI 文献统计, 来自中国学者的贡献数为 42 篇, 约占 $30 \%$. 结合中文文献统计, 中国学者 2018 年发表的总 文献数为 109 篇. 这其中有关湖泊学的 SWI 文章占一大半以上, 使得 “沉积物一水界面” 逐步成为我国湖泊 学的重要研究内容和方向. 最近《湖泊科学》基于 CiteSpace 和知网数据库统计后进行专业评估 ${ }^{[21]}$ : 认为 “沉 积物一水界面元素迁移转化特征与规律, 内源污染对湖泊富营养化的贡献” 是自 1949 年来, 我国湖泊科学领 域可总结出的 6 项较为系统和全面的代表性研究成果之一.

鉴于界面的重要性,近 20 年来国内外对包括湖泊在内的沉积物一水界面过程的研究十分重视 ${ }^{[22-28]}$. 作 为 ELOISE 项目的一部分, 启动于上世纪末的欧洲盐沼模拟计划 (EUROpean SAlt marshes Modelling, EUROSAM) 中, 设置了水底沉积物动力过程和有机质的产生及通量等多项研究内容 ${ }^{[22]}$. 2004-2006 年欧洲科学 基金( ESF) 资助欧洲七国合作开展了一项叫做 SEDFLUX 计划,所列的主题 “Sediment fluxes”、“Sediment budgets” 和“Source-to-sink fluxes/correlations” 都是以沉积物界面为核心 ${ }^{[23]}$. 与此同时,欧盟推出了第 6 次框 架一体化计划 (FP6-AquaTerra 计划) (2004-2009 年), 共有 11 个有关海洋和湖泊等水体的子项目, 其中直 接与界面有关的子项目就达 4 项 ${ }^{[24]}$, 如 BIOGEOCHEM (生物地球化学与界面吸附)、FLUX (沉积物通量确 定) 等. 此外,相关的研究还在其他国家独立展开,如日本学术振兴会(JSPS) 基金资助的用于研发“减少沉 积物、水的营养物流域管理技术”项目 (2005-2009 年) 和法国设立专项研究计划 “ the Microbent-PNEC Program”用于研究 “富营养化环境沉积物一水界面生物地球化学过程” ${ }^{[25]}$ 等. 我国对沉积物一水界面的研究也 十分重视. 早在 “九五”末期国家启动渤海生态系统动力学的重大基金项目中, 就设立了沉积物一水界面与 底栖系统耦合等方面的专题 ${ }^{[26]}$. 我国 “十五”期间, 由科学技术部推出的国家重点基础研究发展计划 (2002CB4123) 和中国科学院推出的知识创新工程重大项目 (KZCX1-SW-12) 中,均专门设立了湖泊沉积物一 水界面过程的研究课题 ${ }^{[27-28]}$, 此后国家自然科学基金委员会 2007 年还首次将 “湖泊中水土界面微环境变化 的过程与机理”纳人重点项目的优先资助领域.

由于以上国内外诸多计划的实施和推进,沉积物一水界面研究的学术性交流也越来越受到重视. 2006 年 BioFlow Network 第二次研讨会后刊出了“Exchange Progress at the Sediment-Water Interface” 专辑 ${ }^{[29]} .2013$ 年美国海洋湖沼学会 (ASLO) 水科学年会上, 针对沉积物一水界面相关的内容就独立地设立了两个分会场 “Biogeochemical Reponses to Human Impacts at the Sediment-water Interface” 和 “Geochemical Consequences of 
Advection of Aquatic Sediment”. 为将国外系统性研究成果介绍到中国, 与湖泊沉积物和水底边界层有关的专 著《Lakes:Chemistry Geology Physics》、《The Benthic Boundary Layer-Transport Processes and Biogeochemistry》 先后被译成中文 ${ }^{[30-32]}$. 与国外学术交流发展相似,2014-2018 年连续 5 届的 “全国沉积物环境与污染控制研 讨会” 均将 “沉积物一水界面” 相关内容作为分会场主题, 2017 年国际环境领域主流刊物《Environmental Pollution》依托该学术平台资源,组织出版了专刊“Sediment and Environmental Pollution”, 其中近 1/2 的文章涉 及沉积物一水界面的研究, 反映沉积物一水界面过程和效应仍是国内外生态环境领域的研究热点问题之一.

\section{2 沉积物一水界面的物理尺度与结构}

界面 (interface) 是相与相之间的交界面, 即两相间的接触表面. 沉积物和水体间固液介质的物理接触并 非仅由狭义的 “界面”一词承接. 物理学上, 分子界面不是指一个几何分界面, 而是指一个薄层. 具体到沉积 物一水界面而言, 其物理尺度不仅涉及到表面(界面), 还涉及到 “厚度” ${ }^{[31]}$. 沉积物内孔隙占据约 $60 \% \sim 90 \%$ 大部分空间, 或几乎均是由水体 (间隙水或孔隙水) 填充, 这就使得沉积物与水之间并非简单以面的方式接 触, 而是两种介质在垂向尺度上的相互渗透和相互包含 ${ }^{[32]}$. 这种广义上的渗透和包含造成 “界面” 在垂向上 拉伸,使界面有了立体尺度.

湖泊沉积物一水界面的上部是湖体水动力主导的混合层, 早期人们都是从与底部水力运动影响相联系 来进行沉积物一水界面垂向结构表征的 (图 2). 从沉积物一侧, McClain 等 ${ }^{[33]}$ 考虑底部湍流导致切应力水压 驱动的达西流 (Darcy flow) 扩散的影响, 并对沉积物表层颗粒作理想多孔排列假设, 从而确定沉积物表层存 在一布林克曼层 (Brinkman layer), 它是一个多孔性介质层, 其厚度 $\left(\delta_{\mathrm{b}}\right)$ 仅约为 $10^{-5} \sim 10^{-3} \mathrm{~cm}$ 量级. 对于沉积 物一水界面以上, 加拿大流体物理学家 Boudreau B.P. 和德国微生物学家 Jørgensen B. B. 对海洋和深水湖为主 要对象的水底边界层 (Benthic Boundary Layer, BBL) 概念进行了较完整的总结和物理尺度的整合 ${ }^{[31]}$, 给出了 一些层的大致尺度 (图 2). 其中确定的对数层 (约 $1 \mathrm{~m}$ 或流动深度)、粘滞亚层 $($ 约 $1 \mathrm{~cm}$ ) 和分子扩散边界层 (约 $1 \mathrm{~mm}$ ) 的垂向尺度,为人们研究水底边界层给出了相对合理的空间量级范围.

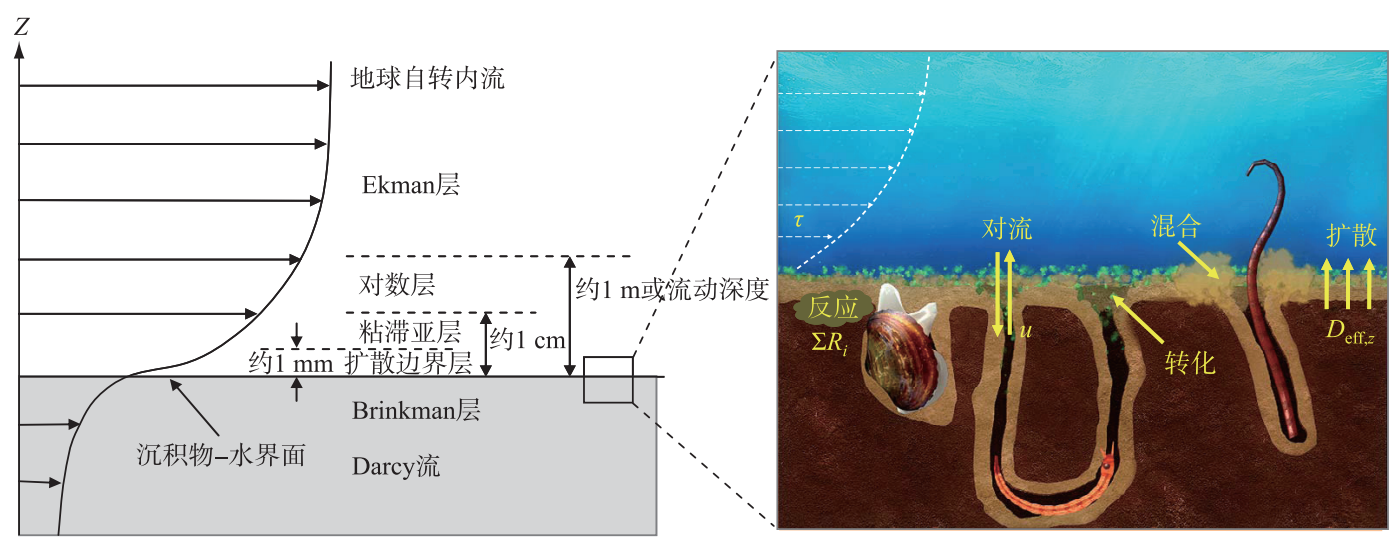

图 2 湖泊沉积物一水界面垂直结构和主要过程及影响示意图

(左图为深水湖水底边界层划分; 右图为水动力和底栖生物扰动的沉积物一水界面)

Fig.2 Vertical structure and main processes of sediment-water interface of lakes and their influence

对于沉积物一水界面厚度的估算, 不同的学者所得结果差异较大. 法国学者 Menard P.B. 和 Martin J.M. 认为, 海洋一沉积物界面是厚度约为 $10 \mathrm{~cm}$ 的表层底泥与下层水体多相体系. 在生产力较高的营养型湖泊, 沉积物一水界面结构远比上述所描述的复杂. 湖底是水流、波浪和能量的主要耗散地, 沉积物一水界面为热 量、溶质和颗粒物的交换和生物的栖息和着生提供场 所 $^{[34]}$. 在浅水湖底, 分子扩散层和粘滞亚层的位置并 不稳定, Brinkman 层也很少能观察到为多孔均匀排列, 一旦有超过临界切应力 $(\tau)$ 的作用, 分子扩散层所依 附的界面沉积物就将发生颗粒物再悬浮. 已有研究表明 ${ }^{[35]}$ 波浪作用下的再悬浮泥沙并非全部来自于沉积 
物表层, 还有一部分来自于沉积物的内部, 通过液化渗流向上输运至表层, 进而被再悬浮, 其贡献量值可达 再悬浮总量的 $50 \%$. 孙永福等根据浅地层剖面探测资料识别水下三角洲粉质泥土扰动位置, 最大扰动深度 为 $4.2 \mathrm{~m}$ (水深 $8 \mathrm{~m}, 10$ 级风). 但经公式计算, 水深小于 $8 \mathrm{~m}$ 时, 水底摩擦的能量损耗开始影响风浪成长, 大 于 $8 \mathrm{~m}$ 时波浪对水底的作用反而减弱, 这两种情况风浪对沉积物孔隙水压力累积导致的残余液化作用下 降, 扰动深度明显变小 ${ }^{[36]}$.

在沉积物一水界面及邻近层位, 微生物和底栖动物的种类和数量通常较为丰富 ${ }^{[37]}$, 早期成岩作用甚为 剧烈 ${ }^{[38]}$, 在一些季节和区域, 藻体还会沉降到沉积物表层 (图 2), 影响沉积物一水界面物质行为 ${ }^{[39-40]}$. 以太 湖藻体和底栖生物为例, 越冬休眠的藻体可以藻席 (algal mat) 形式覆盖沉积物表层, 厚度 $1 \mathrm{~cm}$ 的藻席约相 当于 2000 个藻细胞层在沉积物表层堆积状覆盖, 这还不包括由于扰动造成的表层底泥与藻体的混合影响 尺度. 另据 Teal 等 ${ }^{[4]}$ 对全球主要水域底部由于扰动所产生的物理效应统计, 底栖生物的平均扰动强度 $\left(D_{\mathrm{b}}\right)$ 为 $19.98 \pm 42.64 \mathrm{~cm}^{2} / \mathrm{a}(n=454)$; 扰动深度 $(\mathrm{L})$ 为 $5.75 \pm 5.67 \mathrm{~cm}(n=791)$, 其中水丝蚓掘穴深度可达到 $10 \sim 12 \mathrm{~cm}^{[42]}$. 在太湖, 河蚬 (Corbicula fluminea) 的密度最高可达 $820.0 \mathrm{ind} . / \mathrm{m}^{2[43]}$, 霍甫水丝蚂 ( Limnodrilus hoffmeistteri) 的最高密度可达 $30865 \mathrm{ind} . / \mathrm{m}^{2[44]}$. 这些掘穴生物所产生的大量孔洞和廊道(图 2), 不仅使沉积 物一水界面立体尺度的均一性遭受严重破坏,而且使得界面形态和结构更加复杂 ${ }^{[45]}$.

\section{3 湖泊沉积物一水界面的研究方法及技术}

围绕沉积物一水界面研究所取得的一些成果, 近些年突出表现在对一些新技术和新手段的应用,使得对 界面特性的描述向原位、快速、微观和多维等方向发展. 相关技术的发展极大地促进了沉积物一水界面研究 水平的提高, 反过来, 特有的研究需求也一定程度地推动了相关方法和技术的创新以及装备精细化程度的 提升 ${ }^{[7]}$, 如微量分析技术、材料技术、光电技术、传感器技术、自控仪表技术等. 就沉积物一水界面具体的对象 和过程研究而言, 方法和技术的进展主要集中于沉积物间隙水的被动采样技术 ${ }^{[46-51]}$ 、微界面信息及结构表 征 ${ }^{[52-54]}$ 和界面过程模拟 ${ }^{[55-58]} 3$ 个相对独立的门类.

\section{1 沉积物间隙水取样及信息获取技术}

间隙水是沉积物和水体之间进行物质交换的主要媒介, 对沉积物间隙水的获取是否精细、有效和是否 形成新技术, 一定程度上决定着沉积物一水界面的理论研究和测定水平, 甚至关系到开拓研究领域新的方 向. 对间隙水的获取分为主动和被动两类. 采用离心或抽吸 (如 Rhizon) 等方法 ${ }^{[57]}$ 是常见的主动获取间隙水 的两种方法, 由于过程中氧化还原环境的变化以及产生的向心流而使间隙水的代表性受影响较大, 不仅难 以获得真实的含量, 而且在沉积物一水界面处信息易失真、连续性易受破坏 ${ }^{[58]}$, 近些年逐渐被快速发展的一

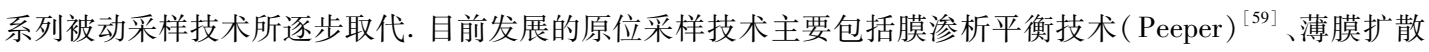
技术 $(\mathrm{DET} / \mathrm{DGT})^{[46]}$ 、半透膜技术等 ${ }^{[51]}$.

最早用于沉积物一水界面的被动采样技术来自于 1976 年 Hesslein 博士的研究 ${ }^{[59]}$, 他根据内外膜渗透平 衡原理发明了平衡式间隙水采样技术 (pore water equilibrators). 该方法利用渗析膜 (dialysis membrane) 或多 孔特氟隆 ( porous Teflon) 材料, 可使得间隙水中离子通过隔断沉积物, 让其中自由离子通过渗析膜进人 Peeper 采样器各腔室的去离子水体中, 最终达到膜两边的离子物质浓度趋于动态平衡, 该技术后来被称为 膜渗析平衡技术 (Peeper). 国外该技术主要用于水深 $<0.5 \mathrm{~m}$ 的沼泽湿地或季节性河流 ${ }^{[60]}$, 界面的垂向分辨 率为 $1 \mathrm{~cm}$, 平衡时间为 2 周左右 ${ }^{[61-62]}$. 为适应湖泊沉积物一水界面的研究, 设计了可用于浅水湖泊的 Peeper 投放装置 ${ }^{[61]}$, 并将经过小型化 (HR-Peeper) ${ }^{[63]}$, 最小垂向分辨率和平衡时间已可达到 $2 \mathrm{~mm}$ 和 1 2 d. 基于 膜渗透平衡原理, 1991 年英国 Davison 博士等研发出了薄膜扩散平衡技术 (Diffusive Equilibration in Thin

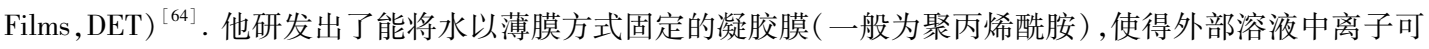
自由扩散到凝胶中, 通过测定凝胶中不同位置离子的含量获取间隙水剖面的信息 ${ }^{[65]}$. DET 技术的优势是使 所需平衡时间缩短 $(<24 \mathrm{~h} / 0.8 \mathrm{~mm}$ 厚 $)$, 空间分辨率大大提高 $(\mathrm{mm} \text { 级 })^{[66-67]}$.

1994 年 Davison 博士与张吴博士合作发明了一项对取样技术具有革命性和产生深远影响的技术一一薄 膜扩散梯度技术 (Diffusive Gradients in Thin Films, DGT ${ }^{[46]}$. 该技术可选择地累计获取包括水土和沉积物一 水界面环境中的溶解性物质, 只与被采集物质在介质中的移动性质和扩散膜特性有关, 因此是一种动力学 
采样技术. DGT 技术的发展主要是围绕高选择性和大容量被测元素固定膜材料进行研发的, 从单一固定膜 分类主要有 3 类,即金属固定膜、氧化型阴离子固定膜和硫固定膜 ${ }^{[58]}$. 金属固定膜主要以 Chelex-100 为固定 剂测定 $\mathrm{Zn} 、 \mathrm{Cd} 、 \mathrm{Cu} 、 \mathrm{Ni}$ 阳离子等金属离子 ${ }^{[68-69]}$. 氧化型阴离子固定膜是以水合金属氧化物/氧化物为固定剂 (如 Fe-oxide、Mersorb、Zr-oxide), 主要测定 $\mathrm{P} 、 A s$ 等 ${ }^{[47,70]}$; 硫固定膜是以 $\mathrm{AgI}(\mathrm{s})$ 为固定 剂, 用于测定可溶性 硫化物 S( II $)^{[71-72]}$. DGT 方法发展 20 年来, 已经广泛应用于环境热点问题的研究, 涉及金属阳离子、阴离 子、有机质及纳米颗粒等信息获取, 同时结合有效的数学模型可以研究各种物质在环境介质中的物理化学 行为及生物有效性 ${ }^{[73]}$. 近 10 多年来, 为同时测定界面附近同一深度位置两种及两种以上目标物质, 研发出 复合固定膜, 如以沉淀型 Fe-oxide 和 $\mathrm{AgI}$ 为固定剂的 $\mathrm{FeO}-\mathrm{AgI}$ 膜测定溶解态 $\mathrm{P} 、 \mathrm{As}$ 和 $\mathrm{S}(\mathrm{II})^{[74]}$, 以 Fe-oxide 和 Chelex-100 为固定剂的 FeO-Chelex 膜, 可以测定无机 $\mathrm{As}$ 和 $\mathrm{Cd} 、 \mathrm{Cu} 、 \mathrm{~Pb}$ 和 $\mathrm{Zn}$ 重金属 ${ }^{[75]}$, 以及以 $\mathrm{Zr}$-oxide 和 $\mathrm{AgI}$ 为固定剂的 $\mathrm{ZrO}-\mathrm{AgI}$ 膜测定溶解态 $\mathrm{P}$ 和 $\mathrm{S}(\mathrm{II})^{[76]}$ 等等.

采用半透膜采样装置 (Semi-Permeable Membrane Device,SPMD) 对沉积物一水界面有机污染物信息被动 采集, 近些年来也得到了迅速发展 ${ }^{[77-82]}$, 并且由于对持久性有机污染物类 (POPs) 的适用性较强而被作为一 种优势被动采样技术. 所采用的半透膜主要有含脂、类脂和不含脂 3 种类型. Tao 等采用三油酸甘油酯-乙酸 纤维素复合半透膜 (TECAM) 结合高效液相色谱一原子荧光, 研究多环芳烃在湖泊沉积物中的含量分布及老 化效应 ${ }^{[78]}$, 并进一步研发出用含湖泊原生水生植物脂的亚油酸包埋醋酸纤维素膜 ( LAECAM) 进行复合的半 透膜, 采集沉积物一水界面的多环芳烃 ${ }^{[79]}$. Bao 等 ${ }^{[80]}$ 在考虑蠕虫降解或对颗粒吞食情景下设计了一种半透 膜采样器, 可对疏水性有机化合物 (HOCs) 原位沉积物一水界面进行被动采样. 另外, 采用不含脂的低密度聚 乙烯膜 (LDPE) 被动采样技术可测定沉积物一水界面一些特殊的溶解态 POPs (如 DDT 和多溴联苯醚) ${ }^{[81-82]}$, 甚至计算得到界面通量. 近年来在开发 DGT 采集有机物方面也取得较大进展, Cole 等 ${ }^{[83]}$ 研发出一种以辛基 硅烷 (C8) 做吸附层的 DGT, 对污染区沉积物孔隙水中 5 种有机锡含量和 DGT 通量进行了研究, 回收率在 $58 \% \pm 10 \% \sim 123 \% \pm 20 \%$ 之间. 集成几种方法的优点开发出新产品是被动式采样器探索的新方向. 最近有人 研发的一种叫做一体化孔隙水注射 (Integrated Porewater Injection, IPI) 采样技术, 它吸收了 Rhizon、Peeper 和流动注射仪 3 者优点, 将一组中空纤维膜管平躺在渍水土壤或沉积物中, 对管周围的孔隙水进行被动和 每 $20 \mathrm{~h}$ 一次的连续取样, 空间分辨率可达到 $2 \mathrm{~mm}$ 水平 ${ }^{[84]}$. 以上沉积物一水界面各种采样技术和分析方法 的发展也不断提升该领域的基础理论研究水平 ${ }^{[85]}$.

\section{2 沉积物一水微界面性质的测定和表征方法}

沉积物一水界面过程的发生大都是以微尺度体现的各种物理、化学和生物效应, 如底栖动物活动可将沉 积物表层从一种简单的层状结构变成一个随时间变化的复杂几何聚集体 ${ }^{[31]}$. 因此对界面微环境、界面微结 构 (甚至三维) 进行精细甚至是原位的表征, 是近 20 年来沉积物一水界面技术研究的重要发展方向之一 ${ }^{[86]}$. 就湖泊沉积物一水界面而言, 这些技术和方法的进展主要集中在微电极测量、断层扫描等技术领域.

当将用于生理学观察的微电极法应用于沉积物后, 人们在沉积物一水微界面异质性方面的视野得到极 大的开拓, 改变了人们对沉积物水平 (或斑块性) 差异的模糊认识 ${ }^{[31]}$. 最新的针式微电极可使氧含量测定的 响应时间 $\leqslant 1 \mathrm{~s}$, 且探针直径已细到完全可忽略其对界面的影响程度 ${ }^{[31-32]}$. 目前应用于沉积物一水界面的微 电极主要是测定沉积物一水界面的氧化还原状态 (Eh) 以及 $\mathrm{O}_{2} 、 \mathrm{H}_{2} 、 \mathrm{H}_{2} \mathrm{~S} 、 \mathrm{~N}_{2} \mathrm{O}$ 等气体含量 ${ }^{[54,58]}$. Gundersen 和 $\mathrm{J} ø \mathrm{rgensen}{ }^{[87]}$ 用分辨率达 $0.025 \mathrm{~mm}$ 的 $\mathrm{O}_{2}$ 微电极对沉积物的扩散亚层 (即有效扩散边界层厚度 $\delta_{e}$ ) 进行高精 度测量, 同时他们还用 $\mathrm{O}_{2}$ 微电极对覆有微生物垫、且复杂 “陡峭” 的沉积物表面成功进行了微地形三维测 量 ${ }^{[31-32]}$. 可用于沉积物一水界面信息获取的另一项新技术是平面光电极技术 (Planar Optode, PO), 也是发展 较为迅速的一种可原位实时监测的二维技术. PO 技术基于苂光分析原理, 在特定激发光源作用下, PO 传感 膜可释放出独特的苂光信号, 并利用数字成像技术可对其二维光谱特征进行实时记录, 最终通过数据处理 测量出目标物质的二维空间动态分布信息 ${ }^{[88-90]}$. 该技术可对复杂的沉积物一水界面 $\mathrm{pH} 、 \mathrm{O}_{2} 、 \mathrm{~T} 、 \mathrm{H}_{2} \mathrm{~S} 、 \mathrm{NH}_{4}^{+}$等微 环境信息具有极高灵敏度和选择性. 另外, DET 和 DGT 技术结合切片和提取或直接显色、薄膜探针和光学 扫描技术等,也可较好地用于沉积物间隙水的信息二维表征 ${ }^{[91-94]}$. Bennett 等用 DET 技术原位比色测量了沉 积物间隙水中铁 ( II ) 的二维分布 ${ }^{[91]}$, Cesbron ${ }^{[92]}$ 用薄膜探针结合高光谱分析孔隙水中磷和铁, 以及 Gao 等 ${ }^{[93]}$ 用薄膜探针和光学扫描技术分析缺氧沉积物中溶解硫化物和金属的关系, 都较精细地给出了二维图 
像. 对特殊区域如根际环境的二维分析, Wang 等 ${ }^{[95-96]}$ 用 DGT 技术、Han 等以平面光电极技术分别表征了沉 积物 (间隙水)一水界面磷、硫和重金属的含量分布, 以及苦草根系泌氧和小分子有机酸的分泌的变化 过程 ${ }^{[90]}$.

底栖生物的扰动对沉积物形态的影响是立体式的生物改造 (reworking), 被现代生态学理论认为是 “生 态系统工程” 的典型实例 ${ }^{[97]}$, 它对沉积物表层的破坏作用比水动力物理扰动要大得多 ${ }^{[53,98]}$, 通过挖穴、摄 食、通风、排泄和搬运等过程, 可对沉积物构筑成有管、孔、穴等组成的立体廊道 ${ }^{\left[{ }^{[4,98-99]}\right.}$, 甚至形成上下层颗粒 混合和间隙水性质 “短路” ${ }^{[100]}$, 实现着改变地球化学梯度的影响作用 ${ }^{[97]}$. 对沉积物生物扰动物化测定和结 构表征的研究方法大多来自于海洋. 王英国和王珍如 ${ }^{[101]}$ 根据底栖生物丰度和分异度变化, 通过精细观察区 分了生物对表层沉积物构造所产生的垂向破坏作用. 人为引人示踪颗粒物是沉积物生物扰动形态表征的常 用方法, 比如人为添加重矿砂示踪颗粒 ${ }^{[102]}$ 、同位素标记的沉积物颗粒 ${ }^{[103]}$ 、有机质和掺杂金属的沉积物颗粒 等 ${ }^{[104]}$. 范德江等 ${ }^{[105]}$ 利用高分辨 X-ray 成像技术对受生物扰动影响的浅表沉积层构造进行了成像. 在监测 沉积物中苂光示踪颗粒运动方面, 沉积物剖面成像 (sediment profile imaging, SPI) 技术得到应用, 该技术可以 高时间分辨率 $(\min \sim \mathrm{h})$ 与高空间分辨率 $(\leqslant 250 \mu \mathrm{m})$ 进行精细化分析 ${ }^{[106]}$. 对表层沉积物廊道的三维表征难 度要大得多 ${ }^{[45]}$, 在形成孔穴和廊道的沉积物中, 由于孔穴中的通风情况以及生物种类数量等不同, 会产生氧 化还原体系的波动 ${ }^{[107]}$.

\section{3 沉积物一水界面静态和动态过程模拟方法}

对沉积物一水界面过程模拟分静态和动态两大类方法. 常见的静态模拟是控制柱状沉积物/水体系的环 境条件 (如温度、 $\mathrm{pH}$ 、溶解氧、微生物等)下, 所进行的异位培养 ${ }^{[85,108]}$. 在浅水湖过程模拟实验中, 一种流动界 面稳态培养技术获得应用. 该技术通过控制沉积物上覆水温度、营养离子及溶解氧等气体含量, 或引入同位 素技术 ${ }^{[109-110]}$, 不仅能精细、准确地跟踪沉积物一水界面溶质的迁移, 而且对有氧气参与的呼吸光合作用、氮 气参与的固氮反硝化作用, 甚至一些挥发性有机物的界面交换, 都可以通过流动培养模拟实现. 另外, 在体 系中引人 Peeper/DET/DGT 等垂向高精度间隙水取样技术 ${ }^{[85,111-112]}$, 目前在沉积物异位培养方面也成为趋 势, 以获取过程模拟中更多有效信息或帮助对界面物质迁移转化机理的解释. 为避免异位模拟在氧化还原、 光、微生物甚至水压环境与实际湖底差异过大, 原位放置水底培养箱 (benthic chamber) 形成密闭环境的方法 往往被应用 ${ }^{[113-114]}$. Brink 等在密闭的培养箱中增加了水体流运性 ${ }^{[115]}$, Zaaboub 等引人了定时取样技术 ${ }^{[116]}$, 使得水底条件接近实际, 人员操作更加简便, 模拟结果也更为接近真实.

沉积物一水界面的动态影响因素主要有两类, 即物理扰动和生物扰动. 水动力是以层状影响沉积物的, 而底栖动物是以点、条或块状对沉积物表层形成破坏, 两种扰动作用有很大不同 ${ }^{[7,117]}$. 风浪和湖流是物理扰 动的主要驱动力, 主要目的是会形成在界面附近的沉积物再悬浮. 采用矩形槽、环形槽等设备模仿浅水水体 动力条件对底部边界层影响是一类常用的方法 ${ }^{[118-120]}$. 主要采用重力 ${ }^{[121]}$ 、人造波和水流 ${ }^{[122-123]}$ 和人造 风[124-126] 等方式在槽 (flume) 或室 (chamber) 中形成较稳定的水动力和沉积物再悬浮状态 ${ }^{[32]}$. 当涉及生物体 类 (如植物生长) 时, 环形跑道槽被认为能更好地用于有沉积物再悬浮影响的水动力扰动条件下的试 验 ${ }^{[25,127-128]}$. 但所有实验槽均存在水深过浅 $(<30 \mathrm{~cm}$ )、无法保证沉积物层理的原状性和满足统计学平行等 问题 ${ }^{[32,121-128]}$, 人们设计了活塞盘或旋桨等, 直接对原状柱芯的沉积物一水界面垂 ${ }^{\left[{ }^{[129]}\right.}$ 或斜向 ${ }^{[130]}$ 施以强度 可控的机械作用, 使颗粒物的量及垂向分布在约 $80 \sim 180 \mathrm{~cm}$ 高的水柱内, 形成静风至县风风力强度范围 $(0 \sim 12.9 \mathrm{~m} / \mathrm{s})$ 下的对应动力环境 ${ }^{[131]}$. 对水层分层样品获得悬浮物含量虽然可行 ${ }^{[56]}$, 但会损失实验水体积. $\mathrm{Ha}$ 等 ${ }^{[132]}$ 用 $1.5 \mathrm{MHz}$ 和 $600 \mathrm{kHz}$ 脉冲声学多普勒电流剖面仪, 原位无损耗测定了再悬浮时悬浮物含量在沉 积物一水界面附近底部的精细剖面及其变化.

生物扰动对沉积物一水界面的影响过程早先主要集中在用沉积颗粒位置变化来有效定量和便捷分析方 面. 于子山等 ${ }^{[133]}$ 研制出生物扰动实验系统 (AFS), 研究了扰动对沉积物颗粒垂直分布的影响和双壳类生物 导致的沉降作用; 孙刚等用玻璃珠作为示踪剂研究了沉积物颗粒的垂直运移 ${ }^{[134]}$. 但就过程影响分析而言, 意义更大的是能否对沉积物一水生物扰动系统的动态过程形成控制. Matsui 等 ${ }^{[135]}$ 用生物引灌 (bioirrigation) 模拟系统 (Robolug) 记录对沉积物施以的正负水压脉冲变化, 显示管孔底部的底栖生物掘穴产生了与外部 水体定量交换的引灌作用. 与风力扰动不同, 底栖生物的扰动主要体现在生物功能群的差异 ${ }^{[117,136]}$. 采用颗 
粒混合强度、表层沉积物再加工和扰动深度这 3 个生物扰动指标评估, 底栖生物扰动变化 $75.5 \%$ 可用关键生 物功能群/物种丰度和/或生物量来解释 ${ }^{[37]}$. 张雷等 ${ }^{[45]}$ 制作了可控制水位和可进行微曝气的室内流动培养 系统, 对生物扩散者、向上输送者和生物引灌者这 3 种典型生物功能群的 28 天观察, 结合氧 ( DO) 、氧化还原 电位 $(\mathrm{Eh})$ 和 $\mathrm{Fe}^{2+}$ 等垂向分层和剖面分析, 区分了河蚬、霍甫水丝蚓和中国长足摇蚊 (Tanypus chinensis) 对沉 积物扰动深度和间隙水中氧化还原等性质的动态变化差异. 同时他们还考虑到浅水湖沉积物的界面在生物 扰动持续期间, 不可避免地会随机经历风浪等水动力扰动的叠加作用, 模拟 $3.2 \mathrm{~m} / \mathrm{s}$ 风情下, 河蚬组、螺组、 水丝蚓组水柱中的悬浮物量分别是对照组的 $4 \sim 5$ 倍、3 倍和 1.5 倍 ${ }^{[7,117]}$.

\section{4 湖泊沉积物一水界面物质迁移转化过程研究进展}

物质的迁移转化过程是国内外沉积物一水界面研究中涉及最多的内容. 1992 年《Hydrobiologia》在其 $235 / 236$ 卷中组织 68 篇有关沉积物及沉积物一水界面磷等物质迁移转化的文章集中进行了发表, 其中大多 涉及环境因子 (如温度、光照、水动力和生物扰动; 流域陆源、沉积物的组成及其物理性质、有机质含量; 界面 附近的溶解氧、氧化还原电位和微生物特征等) 对沉积物及沉积物一水界面的影响. 这其中很多文献对当今 的研究仍然产生着指导作用 ${ }^{[9,138-143]}$, 随后的研究也主要从以上几方面展开 ${ }^{[14-145]}$. 然而污染物种类的不同, 相同环境下的物质行为会差异明显 ${ }^{[146]}$. 近 10 多年来, 以特征污染类型为导向的沉积物一水界面迁移转化研 究越来越被细化 ${ }^{[8,143,147]}$. 就趋势而言, 已从主要针对营养物向着重视重金属和持久性有机物方向发 展 ${ }^{[82,110,148-149]}$,使沉积物一水界面的研究向深人和系统化方向推进.

\section{1 沉积物一水界面营养物的迁移转化研究}

磷是湖泊富营养化最主要限制性营养元素. 由于沉积物中的部分无机磷可直接离解成磷源迁移到水 体 ${ }^{[9]}$, 因此大量研究围绕无机磷结合形态与界面迁移活性展开. 通常认为铁结合态磷作为最活跃的磷组分, 在缺氧条件下释放的水溶性磷将是参与界面磷迁移的直接来源 ${ }^{[150-151]}$. Hupfer 和 Lewandowski ${ }^{[144]}$ 认为, 对于 那些氧化还原不敏感的 P-结合体系, 如 $\mathrm{Al}(\mathrm{OH})_{3}$ 和不可还原的 $\mathrm{Fe}(\mathrm{III})$ 矿物, 即使在缺氧环境也能完全阻止 磷的释放; 并且还认为钙结合态磷的溶解和有机磷的分解等选择性释放可能比氧化还原驱动的 Fe 耦合磷 循环更为重要. 龚梦丹等 ${ }^{[152]}$ 用 DGT 研究了长江中下游几个典型湖泊, 发现沉积物中有效态磷和 Fe 含量在 垂向上同步变化, 说明磷的释放受 Fe 的氧化还原过程控制. 对沉积物一水界面氮的迁移转化过程的研究, 重 点主要关注引起形态氮在界面附近转化的机理和原因, 迁移只作为结果 ${ }^{[110,153-154]}$. 薛惊雅等用流动培养和稳 定氮同位素示踪对傀佃湖硝酸盐异养还原过程研究发现, 厌氧反硝化是傀儡湖沉积物一水界面生物参与下 的硝酸盐异养还原的主导过程 ${ }^{[110]}$. Zhao 等对洱海沉积物一水界面氮的释放研究反映, 在好氧条件下铵 $\left(\mathrm{NH}_{4}^{+}\right)$可很容易地释放到上覆水中 ${ }^{[154]}$, 周期性的氧化还原波动会导致特定微生物的活性增加、提高有机物 的转化率 ${ }^{[136]}$, 这对那些价态易变元素 (如氮) 在沉积物中有机质的矿化和生物降解中的迁移转化行为影响 最大 ${ }^{[154]}$.

鉴于沉积物一水界面氧化还原环境的重要性,许多研究都将物理或生物扰动作为主要影响因子加以考 虑 ${ }^{[7,45,107,128,155-156]}$, 以期加深动态环境下的机理性研究. 朱广伟等 ${ }^{[122]}$ 用矩形槽模拟波浪对底泥的扰动表明, 在大波作用阶段, 溶解性磷和氨氮可分别增加 $20 \%$ 和 $30 \%$. 尤本胜等 ${ }^{[131]}$ 用旋浆式再悬浮装置定量模拟太湖 水深和风浪, 揭示了大风条件下水体磷酸盐的增量反而低于小风条件, 氮含量甚至呈减小趋势; 风浪过后 $8 \mathrm{~h}$, 水体中的营养盐, 包括悬浮物含量, 基本可恢复至风浪前的初始水平 ${ }^{[56]}$. 在水生植物生长区, 风浪对湖底的 剪应力降低, 沉积物再悬浮可受到一定程度的抑制, 再悬浮期的总磷释放以溶解态总磷为主 ${ }^{[128,157]}$. 生物扰 动对沉积物一水界面过程的影响近些年越来越受到人们的重视, 据 Haese 等 ${ }^{[158]}$ 研究, 沉积物内的平流 ( advection) 速率仅为 $3 \sim 50 \mathrm{~cm} / \mathrm{a}$, 而底栖生物引灌 (bioirrigation) 的深度积分速率则高出对流速率 $1 \sim 2$ 个数量 级. 张雷等 ${ }^{[45,53]}$ 曾较系统地研究了太湖主要代表性底栖生物亚洲蛤 (Corbicula fluminea), 管状蠕虫 (tubificid worms) 和摇蚊幼虫 (Chironomidae larvae) 对沉积物一水界面营养物迁移转化的影响. 结果表明, 不同功能生 物的扰动对沉积物氧的穿透差异较大, 蛤类扰动明显增加沉积物活性磷的释放. 摇蚊幼虫在沉积物能形成 最大长度 $6 \mathrm{~cm}$ 的氧化管 ${ }^{[53]}$, 会使间隙水中的溶解性磷和 $\mathrm{Fe}$ ( II ) 含量显著降低 ${ }^{[159]}$, 隐示着不了解底栖动物 洞穴的分布甚至氧 (DO) 在沉积物中的时空分布及其动力学, 则难以解释生物扰动影响下沉积物一水界面物 
质交换过程和机理 ${ }^{[155]}$. 此外, 细菌不仅通过改变氧化还原条件, 还通过在有机物矿化过程中释放磷以及细 菌磷的积累和释放来影响磷的循环 ${ }^{[143,151]}$. 由于微生物过程消耗氧气并释放磷, 因此很难区分氧气耗尽是磷 释放的结果还是原因 ${ }^{[7]}$.

在营养物的迁移转化过程研究中, 人们往往是将有机态氮磷作为目标物或一并进行的 ${ }^{[11,53,122,147,160-161]}$, 并且也越来越重视微生物和有机物等对营养物在沉积物一水界面行为的驱动作用 ${ }^{[7,11,143,153]}$. 表层沉积物中 有机磷的降解是湖泊中磷最重要再生途径 ${ }^{[144]}$. Valdemarsen 等 ${ }^{[153]}$ 为研究有机氮 $(\mathrm{ON})$ 和有机磷 $(\mathrm{OP})$ 的微 生物矿化过程进行了 2 年的沉积物收集和分析, 发现氮的内源负荷在不到 200 天内就下降到与对照无显著 差异, 而磷的内源负荷则持续到年的时间尺度, 确证微生物矿化是磷来源主要原因. 这说明氮和磷在沉积 物一水界面上的释放机理是不同的,氮的释放取决于沉积物中氮化合物的分解程度. Müller 等 $^{\left[{ }^{[11}\right.}$ 通过外部 添加小分子有机底物, 发现氮和 $\mathrm{Fe}$ ( II ) 的释放都明显增加, 但磷的释放低于实际情况, 从而质疑已建立的铁 磷同步释放的传统认知 ${ }^{[13,138,144]}$. Song 等 ${ }^{[143]}$ 分析了湖泊有机态营养物与微生物、酶和浮游生物等的协同关 系, 发现在低含量水平下刺激微生物胞外酶来分解有机营养物, 以形成为藻类等浮游生物生长提供足够的 无机营养物.

\section{2 沉积物一水界面重金属的迁移转化研究}

由于对水生生态系统及人类健康可直接产生威胁以及具有生物富集性, 重金属在沉积物一水界面的迁 移转化行为是该领域的研究热点之一 ${ }^{[125,148,162-163]}$. 重金属在界面附近的迁移转化行为, 往往与电子的转移或 是氧化还原电位以及有机质的易降解程度等相关联 ${ }^{[164]}$. 同营养物的行为类似, 重金属在沉积物一水界面也 会受物理扰动和生物扰动的影响. 俞慎等 ${ }^{[148]}$ 曾重点对沉积物再悬浮下的重金属释放机制及主要影响因素 进行了较系统的总结, 归纳出有氧环境下沉积物结合态重金属释放的可能机理. 雷阳等 ${ }^{[125]}$ 研究了自然水体 不变价态重金属 $(\mathrm{Ni} 、 \mathrm{Cd}$ ) 在定量模拟的小风、中风和大风扰动条件下的二次释放以及对水生植物 (苦草) 的 影响, 结果认为所有风浪强度和植物存在条件下, 沉积物间隙水中的 $\mathrm{Ni}$ ( II ) $\mathrm{Cd}($ II ) 含量均减少, 表明动力 再悬浮也会使得间隙水中的重金属产生释放. Xie 等 ${ }^{[165]}$ 用 X 射线吸收光谱 (XAS) 对结合态锌分析表明,再 悬浮增加了锌从矿物相中的溶解, 表层沉积物的氧化促进水合态 $\mathrm{Zn}$ ( II ) 的形成, 认为从矿物相溶解下的重 金属向间隙水的稳定输送和向上覆水释放与阵发式再悬浮产生的细颗粒重金属的释放都同等重要. 在沉积 物下层或近表层厌氧环境中, 有机质是在厌氧微生物作用下以 $\mathrm{NO}_{3}^{-} 、 \mathrm{SO}_{2}^{-}$等为电子受体而被降解, 速率相对 缓慢, 有机质结合态重金属的释放可以忽略; 但在有氧环境下, $\mathrm{O}_{2}$ 取代 $\mathrm{NO}_{3}^{-} 、 \mathrm{SO}_{4}^{2-}$ 为电子受体, 好氧微生物活 性增强, 有机质的氧化降解速率提高, 促进了有机质结合态重金属的释放 ${ }^{[166]}$. Huang 等 $^{\left[{ }^{[123]}\right.}$ 用环形水槽研究 了 4 种重金属在两种流速下的释放,结果发现酸挥发性硫化物 (VAS) 含量高的沉积物,在动力作用下其硫 化物/有机物结合态之比会随时间逐步减少, 说明金属硫化物的氧化是其重金属释放的主要原因.

重金属普遍与硫 $(\mathrm{S}$ ) 在低强度扰动或静态环境下可形成相对稳定的金属硫化物, 而硫以及部分大多数 重金属是多价态的氧化还原环境敏感性元素, 因此其在界面附近的迁移转化行为, 往往与电子的转移或是 氧化还原电位、有机质含量及生物易降解程度甚至 $\mathrm{pH}$ 环境等相关联 ${ }^{[151,167]}$. 朱金山等 ${ }^{[168]}$ 对三峡库区消落 带形态采的扩散研究反映, 相对好氧的环境更有利于无机永从沉积物一水界面释放, 而黑暗厌氧和深水环境 则有利于甲基录的释放. 从微生物机制分析, 厌氧期以硫酸盐还原菌 (SRB) 为主、铁还原菌和含有 $\mathrm{Hg}$ 特定 基因簇的微生物存在, 对沉积物一水界面 $\mathrm{Hg}$ 的甲基化过程起重要作用 ${ }^{[169]}$. Chen 等 ${ }^{[170]}$ 对底部缺氧的深水水 库研究表明, 间隙水中的溶解性锰 $\mathrm{Mn}_{\text {diss }}$ 和 $\mathrm{Mn}$ ( III ) 与上覆水中存在明显的浓度梯度, 隐含 $\mathrm{Mn}(\mathrm{III})$ 有较强的 界面释放行为发生. 作为重金属之一同时又是环境敏感性元素, 锰往往在沉积物一水界面担负着特殊角色. Fan 等 ${ }^{[171]}$ 用 DGT 技术室内研究了沉积物一水界面形态 Cr 含量及分布, 结果表明 Cr 的迁移性与 Mn 的氧化 还原状态和有机质含量有关. 冬季好氧, $\mathrm{Mn}(\mathrm{III} / \mathrm{IV})$ 氧化物对 $\mathrm{Cr}(\mathrm{III})$ 氧化, 使溶解态 $\mathrm{Cr}$ 与 DOM 含量呈同步 增加; 夏季沉积物厌氧, Cr 与溶解性有机质 (DOM) 呈络合态存在. Yan 等 ${ }^{[163]}$ 同样用被动采样技术现场调查 了不同营养水平湖区沉积物一水界面 As-Fe-Mn 形态含量, 观察到不稳定态砷与铁、锰之间存在正相关关系, 揭示砷的结合态铁、锰氧化物在沉积物中的还原溶解是导致沉积物砷释放的主要原因.

与再悬浮高强度扰动相比较, 生物扰动对沉积物虽然属于低强度物理破坏, 但通过摄食、排泄等行为, 会造成富集在沉积物中的重金属再次释放到水体形成“二次污染”. 生物功能群的不同,对重金属在沉积 
物一水界面的环境行为的影响也就各不相同. 在底栖生物功能群中向上输送者和生物引灌者这两类, 可将底 部沉积物搬运到表层或是将水体引灌到孔道底部, 从而使得沉积物接触到更充分的氧 ${ }^{[7,32]}$. 搬运到界面上 的底部沉积物也可以在水动力作用下再悬浮进人上覆水, 生物引灌到沉积物洞穴内部的氧改变着体系的氧 化还原环境和氧动力学过程 ${ }^{[45]}$, 从而对沉积物一水界面附近重金属的迁移转化行为产生着影响. 国内外对 水层一底栖界面耦合过程的研究已开展多年 ${ }^{[26]}$, 何怡等曾以表格形式对 12 种常见重金属受不同功能群生 物扰动所造成的影响, 对前人相关工作做出了较系统的总结 ${ }^{[172]}$, 指出底栖生物通过运动、摄食、排泄等可能 导致沉积物颗粒再悬浮、向沉积物内部输人新鲜上覆水与氧气、改变沉积物物理化学性质等, 从而影响重金 属向上覆水中释放.

\section{3 沉积物一水界面有机污染物的迁移转化研究}

有机污染物分天然和人工合成两大类. 湖泊沉积物中常见的天然有机物主要为碳水化合物、蛋白质、氨 基酸以及脂肪等, 这些物质往往是湖泊中甚至流域内死亡的植物、动物和微小生物等经不同氧环境下化学 或生物分解后的产物, 最终作为沉积物中有机质的主要组成部分 ${ }^{[164]}$. 在沉积物中及其在与水形成界面上, 几乎所有的营养物和重金属迁移转化行为都与有机质的分解或早期成岩活动有关 ${ }^{[7,31-32,38]}$. 比如沉积物一水 界面磷转化往往是 (含磷) 有机质降解或矿化使有机磷转化成无机磷形成磷释放 ${ }^{[164,173]}$. Zhang 等 ${ }^{[173]}$ 研究了 水生植物 (浮萍) 碎屑在沉积物一水体系中的降解, 结果表明植物碎屑的分解在沉积物一水界面处介导了磷 的转化, 形成在表层沉积物磷的释放. 水动力或生物扰动的介人将使得有机质降解所产生的相关物质的行 为变化更加复杂. Dadi 等 ${ }^{[174]}$ 研究了沉积物再悬浮下溶解有机碳 (DOC)、金属 $(\mathrm{Fe} 、 \mathrm{Mn})$ 和营养物 $(\mathrm{N} 、 \mathrm{P})$ 的底 部通量的响应, 研究表明沉积物再悬浮促进了微生物对有机底物的降解, 导致上覆水体中 DOC 和金属含量 的增加、铵的释放. 能上下搬运沉积物和引灌水体的底栖生物, 都可使埋藏在沉积物中的有机质和重金属重 新活化. $\mathrm{He}$ 等 ${ }^{[175]}$ 用 3 种底栖生物模拟了它们对埋藏在沉积物中有机质、铊、镉、铜和锌的再利用性, 结果反 映生物扰动明显促进了水体中溶解有机物 ( DOM) 和溶解态 $\mathrm{Tl} 、 \mathrm{Cd} 、 \mathrm{Cu}$ 和 $\mathrm{Zn}$ 的释放, 其中以有机态结合的 $\mathrm{Cu}$ 其释放的溶解性 $\mathrm{Cu}$ 与 DOM 组分的相关性最好.

持久性有机污染物 $(\mathrm{POPs})$ 由于具有致癌、致畸、致突变及内分泌干扰等作用,其在沉积物一水界面上的 迁移转化行为, 近些年来已引起人们关注 ${ }^{[80,149]}$. 但由于沉积物中 POPs 不仅种类数量巨大、结构复杂, 而且 普遍含量低具有憎水性, 这对沉积物一水界面的空间代表性和选择性取样就提出了更高的要求, 再加上当今 研究物质的迁移扩散往往还兼有风险和通量评估的要求, 因此在沉积物一水界面 POPs 迁移转化的研究中 普遍含有方法学内容 ${ }^{[51,176]}$. Fernandez 等 ${ }^{[176]}$ 尝试采用 3 种被动取样材料 ( 聚乙膜 PE 条、聚甲醛 POM 条和 半透膜 SPME 纤维), 测定界面附近表层沉积物和上覆水中 DDE、DDD 等多氯联苯 (PCB) 同系物含量, 并比 较它们测量的准确性,计算了它们在沉积物一水界面微边界层的扩散通量. Tao 等 ${ }^{\left[{ }^{[1]}\right.}$ 用亚油酸包埋醋酸纤维 素膜 ( LAECAM) 原位对湖泊表层沉积物间隙水中 10 种 PAHs 在冬夏两季自由溶解浓度进行现场测定, 预测 了在沉积物一水界面附近 PAHs 对 4 种沉水植物的生物可利用性. 为了研究疏水性有机污染物多溴二苯醚 同系物 (PBDEs) 在水体中的通量和归趋, Khairy 和 Lohmann ${ }^{[82]}$ 测定了包括沉积物、间隙水和上覆水中天然 吸附剂在内的含量, 结果反映只有 $5 \%$ 的 PBDEs 是真正溶解的, 绝大多数是吸附在沉积物和悬浮颗粒的有机 碳 $(O C)$ 和黑炭 $(B C)$ 中, 并采用 $O C+B C$ 方法计算了沉积物一水界面 PBDEs 的扩散通量. 彭书传等 ${ }^{[177]}$ 则以 低密度聚乙烯膜( LDPE) 为吸附相的原位被动采样器, 采集并分析了巢湖南淝河人湖口处上层水体和沉积 物孔隙水中 13 种多环芳烃 (PAHs) 浓度, 并计算了它们在沉积物一水体界面的分子扩散通量. 结果反映, 大 多数 PAHs 处于从沉积物向水体释放状态, 反映底部沉积物是上层水 PAHs 的二次污染源.

在沉积物一水界面 POPs 的迁移转化行为研究方面, 目前主要还是集中于界面环境特别是物理和生物 扰动影响方面 ${ }^{[149,178-180]}$. 污染物在沉积物中的埋藏深度越深, 生物扰动导致的污染物迁移越弱, 所显示出来 的生物扰动效应就越小. 底栖动物的生物引灌对溶解度高的化合物影响明显, 而产生颗粒物的移动搬运则 对疏水性化合物的影响较大 ${ }^{[172]}$, 而绝大多数 POPs 是属于疏水性的. Cheng 和 Hua ${ }^{[178]}$ 室内模拟了不同水动 力扰动下再悬浮颗粒物特征与沉积物中四溴双酚 $\mathrm{A}$ ( TBBPA) 的释放关系, 结果表明 TBBPA 的浓度与悬浮 颗粒比表面积 $(\mathrm{SSA})$ 存在显著相关性. 为研究沉积物反复多次的再悬浮一沉降中 POPs 的生物可利用性变 化, Dong 等 ${ }^{[179]}$ 模拟了 3 次再悬浮一沉积的发生过程, 结果反映, 由于每增加一次再悬浮一沉积过程, 都会改 
变悬浮态沉积物粒径,增强絮体的形成, 自由溶解态浓度遵循第 3 次 $>$ 第 2 次 $>$ 第 1 次再悬浮事件的顺序. 即 使沉降结束 $70 \mathrm{~h}$ 后, 在悬浮状态中仍有超过一半总的或自由态 PAHs 存在于上覆水中, 表明再悬浮及其多 次的发生会促进 PAHs 的释放和持续. Zhang 等 ${ }^{[180]}$ 设计了一个有沉积物和泥鱾的微型培养系统, 水中放置 了六溴环十二烷非对映异构体 (HBCDDs) 的微粒标记体和鲤鱼 (Cyprinus carpio), 由于 HBCDDs 有较强的疏 水性, 因此主要在沉积物中, $50 \mathrm{~d}$ 的累积试验后发现,生物扩散者泥鳅的扰动促进了沉积物相关的 HBCDDs 的释放, 同时也使得鲤鱼体内溶解性有机物含量增加.

\section{5 湖泊沉积物一水界面过程效应的模型研究}

发生在湖底沉积物一水界面的环境和生物地球化学过程是涉及湖泊生态系统中最为复杂反应的重要过 程, 界面附近的状态及关键环境要素的变化可极大地影响着物质的转化和可利用性, 并由此对上覆水水质 和生物体产生诸如富营养化、黑臭 (湖泛)、适生性和生态危害等环境风险和效应 ${ }^{[31,38,181-186]}$. 对环境过程和 效应的模型化和定量化研究一直是环境地学中的重要内容. 将沉积物一水界面物质迁移转化的复杂过程以 模型化归纳, 以揭示被研究对象的形态、特征、本质及发展规律; 应用适当的技术方法对物质的迁移转化效 应进行强度性表征, 以获取物质扩散、释放和交换等通量化定量参数.

\section{1 沉积物一水界面过程模型研究}

沉积物一水界面过程主要包含发生在沉积物一水界面及其附近物质的迁移扩散和物质的转化等过程. 1980 年 Berner 基于 Fick 第一定律, 归纳并建立了著名的成岩反应一输送模型 (Reactive transport modeling,

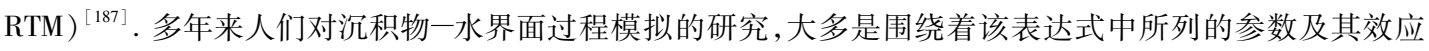
变化过程展开的, 主要涉及扩散项中的扩散层尺度 $(z)$ 、孔隙度 $(\varphi)$ 、有效扩散系数 $\left(D_{\text {eff }, z}\right)$, 平流项中净沉 积和压实作用, 反应项中早期成岩和降解反应式等. 由于微电极、平面光电极和高精度取样等技术的发展, 沉积物一水界面扩散层厚度已可得到较精确的测量 ${ }^{[87]}$. Wang 等 ${ }^{[188]}$ 在总结 DBL 厚度定标方法的基础上, 现 场测量了 3 种动力和氧气环境下的扩散边界层 (DBL) 和底部边界层 (BBL) 尺度, 再考虑水底温度、流速和底 面粗粘度等的测定, 为计算扩散通量提供了可能. 在实际应用中, 成岩反应一输送模型常被简化成只涉及扩 散层厚度 $z$ 和分子扩散系数 $D_{\text {mol }}$ 的 Fick 第一定律 ${ }^{[189]}$ 用于沉积物释放的定量研究 ${ }^{[145-146]}$. 鉴于 Fick 第一定律 只能用于相对静止的水底环境, 对于风浪扰动强烈频繁的浅水湖则会产生极大的误差 ${ }^{[190]}$, Portielje 和 Lijkl$\mathrm{ema}^{[191]}$ 提出在 $D_{\mathrm{eff}, z}$ 中增加扰动扩散系数 $D_{\mathrm{tur}}$ 来表征真实的扰动效应 $\left(D_{\mathrm{eff}, z}=D_{\mathrm{mol}}+D_{\mathrm{tur}, 0} \mathrm{e}^{-a z}\right)$, 并包括了物 理和生物效应在内的扰动影响, 有效地解决了物理扰动效应与经典的成岩反应一输送模型 (RTM) 的整合问 题 ${ }^{192]}$. 张雷等研究不同生物量下河蚬、摇蚊幼虫和水丝蚓扰动与 $\mathrm{NH}_{4}^{+}$和 $\mathrm{PO}_{4}^{3-}$ 扩散系数 $D s$ 的关系, 发现前两 者为线性关系, 后者为对数关系 ${ }^{[7]}$.

1980s 后的 20 多年中, 陆续出现了许多以研究海洋沉积物中溶质分布及可定量化计算界面通量的 RTM 模型 ${ }^{[31,193]}$, 这些模型主要包括:生物湍流扩散模型、生物平流模型、内部源一汇或异地迁移模型以及微环境洞 穴几何模型等及其改进型. Kasih 等 ${ }^{[193]}$ 在修改的 RTM 中, 速率表达式考虑了有机质氧化分为氧化呼吸、反硝 化和铁、锰和硫酸盐的还原, 发现有机质和氢氧化铁的沉积通量、迁移参数、溶解有机质的矿化率等对目标物 质含量的计算有很大影响. Torres 等 ${ }^{[182]}$ 基于底层永久氧化和缺氧环境, 建立了包含一组平衡和动力学生物地 球化学反应的一维非稳态 RTM 模型,分析了微量金属在酸性条件下沉积物一水界面铁、锰(氧)氢氧化物和金 属硫化物的沉淀、分解和释放的归趋过程. Cheng 等 ${ }^{[194]}$ 考虑了吸附/解吸作用, 根据不同粒径和水力条件, 采用 耦合的 Navier-Stokes 方程、达西方程、溶质输运方程和吸附/解吸方程等, 建立了污染物释放的数学模型. 通过 水槽实验发现, 虽然稳定阶段分子扩散浓度约为对流扩散浓度的 1 4 倍, 但初始阶段对流扩散的瞬时浓度比 分子扩散的瞬时浓度大 6 50 倍左右. Ordoñez 等 ${ }^{[195]}$ 考虑溶解氧和湍流在扩散边界层中对初级生产、生化消耗 和扩散的重要性,建立了具有光合作用层和生化反应消耗层的浅水沉积物一水界面溶解氧交换模型. Voermans 等 ${ }^{[196]}$ 从流量对沉积物一水界面物质传输的重要性角度, 通过对水底流体力学的测量, 提出了一个与界面质量 传输空间相关的力学模型,表明有分子传输、分散传输或湍流传输主导 3 种传输方式存在.

在所有 RTM 模型研究中, 关于磷的机理性模型相对系统和完善. Schauser 等考虑沉降变化的沉积物表 层磷滞留量及磷成岩作用, 建立了可模块化的确定性磷成岩模型 (SPEIL), 该模型可添加其他子模块计算好 
氧层厚度、铁硫循环、铝的 $\mathrm{P}$ 吸附能力、孔隙和上覆水磷浓度变化等 ${ }^{[181]}$. 为了阐明热力学和动力学因素对沉 积物磷释放通量的影响, Katsev 等在 RTM 模型中加人了溶解氧和硫酸盐对磷行为的影响 ${ }^{[197]}$, 将剖面磷分布 和界面磷过程视为平衡状态, 建立了一个适合较长时间尺度预测磷释放的模型, 克服了实验室短期或原位 培养研究的不足. 为研究沉积物早期成岩稳定状态中的氧流向, Wang 和 van Cappellen 建立了一个 STEAYSED1 多组分 RTM 模型 ${ }^{[198]}$, 结合实测结果模拟后认为, 水底氧通量受生物扰动和引灌 (irrigation) 的影响较 大, 沉积物吸收的氧气中 $22 \% \sim 46 \%$ 是直接耦合到有机碳的氧化, 剩余的则主要消耗于系统中 $\mathrm{Fe}$ ( II) 和 Mn (II) 等还原性组分的二级氧化. 对于许多湖泊, 沉积物一水界面上发生的各种反应很少能够达到真正意义 上的稳定和平衡, 因此非稳态的动力学模型更适合于短时间尺度内界面磷过程的描述 ${ }^{[45,56,199]}$. Reed 等 ${ }^{[34]}$ 将生物扰动系数 $\left(D_{\mathrm{b}}\right)$ 和孔隙度 $(\varphi)$ 相联系, 建立了 Fe-P-S 化学反应的 25 个化学组分的质量平衡方程及与 沉积物与水柱反馈作用 ${ }^{[200]}$ 的多组分模块, 较好地在 RTM 中综合了固液生物扰动的泥层和水层耦合作用下 磷的成岩反应和输送行为. Doan 等 ${ }^{[183]}$ 应用 RTM 模型研究了安大略五分之一湖湾沉积物 P 的动力学, 量化 了沉积物 $\mathrm{P}$ 结合形式的时空变异性, 估算了不同区域 $\mathrm{P}$ 的扩散通量, 认为沉积物磷释放的驱动机制主要来 自氧化还原敏感性磷和有机结合态磷的成岩循环过程.

\section{2 沉积物一水界面物质交换的定量化研究}

对沉积物一水之间物质通量的计算方法最早由 Berner 提出, 不久 Lerman ${ }^{[4]}$ 从试验学角度对沉积物一水 界面开展了颗粒物沉降、侵蚀和化学物质的界面交换通量等研究, 并对该方法进行了完善. 随着科技成果应 用需求的日益增加, 以沉积物释放速率 (通量) 和内源负荷的定量化内容, 在沉积物一水界面过程和效应的 研究中越来越受到人们的重视 ${ }^{[7,201]}$. 界面的定量化主要针对的是溶解性物质, 通过定量可确定沉积物中有 多少再生或在活化的溶解物质通过沉积物一水界面返回上覆水以及可被生物利用 ${ }^{[96]}$, 这种定量将可判断湖 泊甚至流域物质的历史沉积对水体的影响程度以及对总负荷量的贡献. 关于沉积物一水界面物质交换的定 量化方法国内外主要有质量衡算法 (Mass balance model)、表层沉积物培养法 (Surface sediment incubation)、 沉积物柱芯培养法 (Core sediment incubation) 、水底培养箱法 (Benthic chamber)、分子扩散模型法 (Molecular diffusion model)、反应一输送模型法 (RTM)、天然同位素法 (Natural isotope)、动力水槽法 (Dynamic flume) 和 动力再悬浮法 (Dynamic resuspension) 这 9 类方法. 这些方法中若按原理可分为理论法和实验法, 除较多偏 向于模型和计算的质量衡算法、分子扩散模型法和反应一输送模型法外, 其他均为实验方法; 若按模拟对象 的状态分则可分为静态法和动态法, 除动力水槽法和动力再悬浮法外, 其他几乎均为静态法. 各种方法的条 件和优缺点见表 1 .

质量衡算法又称野外调查分析法, 它是通过对流域工业、城乡生活、畜禽养殖、旅游等点源, 以及农业生 产、大气沉降等面源的调查与分析, 利用差值法进行的估算 ${ }^{[202-203]}$; 表层沉积物培养法 ${ }^{[45,110,140,204]}$ 和柱状沉积 物培养法 ${ }^{[205-206,131,112]}$ 是指对采集的表层和柱状芯样沉积物分别进行控制环境条件 ( $\mathrm{pH} 、 \mathrm{DO}$ 、温度、光照等) 下在室内进行静态或动态环境下的模拟培养实验,通过测定和计算上覆水或水柱中含量和变化得到单位面 积或质量的释放速率; 水底培养箱法是在水底放置可取样箱体, 使其嵌人沉积物形成密闭环境, 形成与水底 几乎同样的环境进行原位培养, 获取沉积物释放通量 ${ }^{[55,113]}$; 分子扩散模型法又称浓度梯度法, 通过取得较 高垂向分辨率的间隙水及其目标物质含量, 利用 Fick 第一定律进行计算获得释放速率 ${ }^{[209]}$. Bozau 等 ${ }^{[216]}$ 研 究温度 $\left(0 \sim 18^{\circ} \mathrm{C}\right)$ 和浓度势边界层厚度 $(Z$ 分别为 $1 、 10 、 25$ 和 $100 \mathrm{~mm})$ 对 Fick 第一定律中扩散参数 $D_{0}$ 值的 影响后发现, $Z$ 值的影响远大于温度的影响, 计算好释放速率, $Z$ 值的取舍对获得正确的结果非常重要. 反 应一输送模型法是考虑沉积物成岩反应和界面扩散 (有时也包括平流) 过程, 通过参数选取反应式构建以及 部分结合沉积物和间隙水分析, 完全用模型方式模拟计算释放速率 ${ }^{[183]}$; 天然同位素法是选用天然放射性或 稳定同位素在沉积物间隙水和上覆水中的时空分布, 选用合适的方法计算间接获得沉积物释放信息. 这其 中同位素法是近些年才出现的新方法 ${ }^{[213]}$, 它主要是依据通过沉积物的物质输人, 通过沉积物一水界面孔隙 水交换和水底地下水的排放,相当于分别来自 “自生”溶解物质和 “外源”物质两个不同途径. 此外还有研究 尝试建立用 DGT 信息导出沉积物通量模型的方法 (DIFS), 但因未能将沉积物一水界面下间隙水和沉积物中 游离态物质含量进行真正意义上的区分, 计算出的 “表观” 通量 ${ }^{[217-218]}$ 作为实际通量的参考. 
表 1 沉积物一水界面内源释放通量估算方法及其比较

Tab.1 Estimation methods and comparison of endogenous release fluxes at sediment-water interface

\begin{tabular}{|c|c|c|c|c|}
\hline 方法 & 条件 & 优点 & 缺点 & 参考文献 \\
\hline $\begin{array}{l}\text { 质量衡算法 (Mass } \\
\text { balance model) }\end{array}$ & $\begin{array}{l}\text { 需对出人湖量进行收 } \\
\text { 支平衡, 需有足够采 } \\
\text { 样点和采样频次 }\end{array}$ & $\begin{array}{l}\text { 人湖河道少时简单, 无需 } \\
\text { 沉积物方面的信息 }\end{array}$ & $\begin{array}{l}\text { 工作量大, 估算精度取决于 } \\
\text { 外源结果的精准程度, 不能 } \\
\text { 获知内源通量的空间分布 }\end{array}$ & [202-203] \\
\hline $\begin{array}{l}\text { 表层沉积物培养法 } \\
\text { ( Surface sediment } \\
\text { incubation) }\end{array}$ & $\begin{array}{l}\text { 需要实验条件可控, } \\
\text { 一般需配备有流动培 } \\
\text { 养设备 }\end{array}$ & $\begin{array}{l}\text { 简单, 可进行静态和动态 } \\
\text { (生物扰动) 培养, 分析较 } \\
\text { 准确, 可结合同位素技术 } \\
\text { 和被动采样技术 }\end{array}$ & $\begin{array}{l}\text { 沉积物原状层理以及物理、 } \\
\text { 化学和生物性状破坏, 实验 } \\
\text { 前的体系稳定时间难以确定 }\end{array}$ & $\begin{array}{l}{[45,110,140,} \\
204]\end{array}$ \\
\hline $\begin{array}{l}\text { 沉积物柱芯培养法 } \\
\text { ( Core sediment in- } \\
\text { cubation) }\end{array}$ & $\begin{array}{l}\text { 样品需无扰动采集和 } \\
\text { 转运, 实验条件能达 } \\
\text { 到可控要求 }\end{array}$ & $\begin{array}{l}\text { 能基本保证沉积物原状 } \\
\text { 性,可模拟多种环境条件 } \\
\text { 和进行多组平行实验 }\end{array}$ & $\begin{array}{l}\text { 样品采集后需立即实验, 回 } \\
\text { 补取样体积易引人误差, 实 } \\
\text { 验体积小易产生壁效应 }\end{array}$ & {$[112,205-207]$} \\
\hline $\begin{array}{l}\text { 水底培养箱法 } \\
\text { ( Benthic chamber) }\end{array}$ & $\begin{array}{l}\text { 需有水底培养箱, 推 } \\
\text { 荐有自带内部水力流 } \\
\text { 动装置 }\end{array}$ & $\begin{array}{l}\text { 接近实际湖底环境, 实时 } \\
\text { 获取水底含量变化信息 }\end{array}$ & $\begin{array}{l}\text { 复杂, 改变了氧化还原和水 } \\
\text { 动力条件, 系统环境条件难 } \\
\text { 掌控, 布设和回收难度大, 费 } \\
\text { 用较高 }\end{array}$ & $\begin{array}{l}{[55,111,113-} \\
114,208]\end{array}$ \\
\hline $\begin{array}{l}\text { 分子扩散模型法 } \\
\text { ( Molecular diffusion } \\
\text { model) }\end{array}$ & $\begin{array}{l}\text { 有较高垂向分辨率的 } \\
\text { 被动采样工具, 平衡 } \\
\text { 时间在 } 1 \sim 15 \mathrm{~d} \text { 之间 }\end{array}$ & $\begin{array}{l}\text { 相对简单和易操作, 可在 } \\
\text { 室内模拟或现场 (浅水 } \\
\text { 区) 进行原位实验 }\end{array}$ & $\begin{array}{l}\text { 垂向分辨率精度要求高, 扩 } \\
\text { 散距离 } Z \text { 的取值随意性大, } \\
\text { 浓度梯度呈线性变化的假设 } \\
\text { 很难保证, 需微量分析条件 }\end{array}$ & $\begin{array}{l}{[112,207,209} \\
210]\end{array}$ \\
\hline $\begin{array}{l}\text { 反应一输送模型法 } \\
\text { (RTM) }\end{array}$ & $\begin{array}{l}\text { 至少需有沉积物物化 } \\
\text { 和相关化学热力学参 } \\
\text { 数及目标物形态、结 } \\
\text { 合态等信息 }\end{array}$ & $\begin{array}{l}\text { 可对复杂体系 (如成岩、 } \\
\text { 扰动等) 长效模拟, 可揭 } \\
\text { 示物质在界面的迁移特 } \\
\text { 征、机制及规律 }\end{array}$ & $\begin{array}{l}\text { 复杂, 参数多, 取值难; 物质 } \\
\text { 初始含量和形态仍需分析, } \\
\text { 结果需要实验修正或验证 }\end{array}$ & $\begin{array}{l}{[34,183,197,} \\
211-212]\end{array}$ \\
\hline $\begin{array}{l}\text { 天然同位素法 } \\
\text { ( Natural isotope) }\end{array}$ & $\begin{array}{l}\text { 需有放射性同位素实 } \\
\text { 验装备和分析条件 }\end{array}$ & $\begin{array}{l}\text { 可开展有底栖生物扰动 } \\
\text { 影响的实验 }\end{array}$ & $\begin{array}{l}\text { 复杂,与其他方法的可比性 } \\
\text { 还有待完善 }\end{array}$ & {$[210,213-215]$} \\
\hline $\begin{array}{l}\text { 动力水槽法 } \\
\text { (Dynamic flume) }\end{array}$ & $\begin{array}{l}\text { 需有矩形或环形槽以 } \\
\text { 及能形成重力、人造 } \\
\text { 波、水流和风等作用 } \\
\text { 的配套设备 }\end{array}$ & $\begin{array}{l}\text { 能形成不同强度的稳定 } \\
\text { 水动力环境, 可用于模拟 } \\
\text { 沉积物动态释放以及有 } \\
\text { 水生植物的影响过程 }\end{array}$ & $\begin{array}{l}\text { 成本高, 模拟水深较浅 (一般 } \\
<30 \mathrm{~cm} \text {, 沉积物的物理、化 } \\
\text { 学和生物的原状性难以保 } \\
\text { 证, 水动力环境与实际对应 } \\
\text { 的难度较大 }\end{array}$ & $\begin{array}{l}{[157,120-123,} \\
125-126]\end{array}$ \\
\hline $\begin{array}{l}\text { 动力再悬浮法 } \\
\text { ( Dynamic resuspen- } \\
\text { sion) }\end{array}$ & $\begin{array}{l}\text { 需有直接对沉积物- } \\
\text { 水界面施以垂向或斜 } \\
\text { 向作用力的装置和控 } \\
\text { 制设备, 样品需无扰 } \\
\text { 动采集和转运 }\end{array}$ & $\begin{array}{l}\text { 基本保证沉积物原状性, } \\
\text { 能定量形成与风速对应 } \\
\text { 的水动力环境, 适宜模拟 } \\
<2 \mathrm{~m} \text { 水深、满足统计学 } \\
\text { 平行的过程研究 }\end{array}$ & $\begin{array}{l}\text { 成本较高, 易产生壁效应, 难 } \\
\text { 以模拟再悬浮动力的剪切作 } \\
\text { 用, 回补取样体积易引人 } \\
\text { 误差 }\end{array}$ & {$[117,129,131$} \\
\hline
\end{tabular}

Smith 等用 ${ }^{137} \mathrm{Cs}$ 作为扩散物质,室内外研究了其在沉积物中的扩散速率, 结果发现, 室内模拟获得的 Cs 在沉积物一水界面的扩散速率较原位柱样模拟获得的速率高出一个数量级以上 ${ }^{[213]}$. Cai 等采用天然放射性 同位素体系—— ${ }^{224} \mathrm{Ra} /{ }^{228} \mathrm{Th}$, 运用不平衡法原理建立了沉积物通量估算方法,估算了沉积物一水界面溶解无 机碳、营养盐和痕量金属等物质交换量 ${ }^{[214]}$. Shi 等 ${ }^{[215]}$ 采用 ${ }^{224} \mathrm{Ra} /{ }^{228} \mathrm{Th}$ 不平衡法和其他方法对比分析中国沿 海水底铁通量表明,该法较分子扩散模型法结果也大致高一个量级. 最近陈敬安课题组基于磷酸盐中 P-O 键的高稳定性, 测定了红枫湖水体、典型外源和沉积物间隙水中的磷酸盐氧同位素 $\left({ }^{18} \mathrm{O}\right)$ 组成, 进而分析了 内外源的特征氧同位素值, 利用端元混合模型定量计算了红枫湖沉积物内源磷对湖泊水体磷的贡献 ( $40.5 \%)$, 结果与沉积物柱芯培养实验和 HR-Peeper 被动采样监测结果较为接近 (会议交流成果未发表), 该法具有野外调查分析法和天然同位素法混合特征. 此外,动力水槽法和动力再悬浮法的原理和优缺点,在 前面和表 1 中已有较详细的介绍和说明, 近年来的研究成果反映, 这两类模拟方法越来越得到重视和应用. 


\section{3 沉积物一水界面过程与湖泊生态环境灾害的关系研究}

随着自然特别是人类活动强度的加剧, 湖泊流域的环境压力不断增加, 重大生态环境灾害问题, 包括藻 类暴发、沼泽化、湖泛等湖泊富营养化及水质恶化问题, 以及重金属和持久性有机污染等湖泊生态风险危害 等也频有出现. 沉积物是与湖泊水体接触面最大的介质, 对上覆水体既可扮演成 “汇” 也会显露出 “源”. 已 有的研究发现, 在上述渐进性或突发性湖泊灾害中, 沉积物或主动或被动地参与到其中, 甚至扮演着关键角 色. 沉积物一水界面及其附近突发性物理事件、化学物质蓄积和生物体积聚环境等, 都可能是猝发或诱发极 端污染和生态灾害事件的关键因素.

对表层沉积物的物理性侵蚀,有可能会使沉积物一水界面常稳态、低通量的污染物交换汇集成“瞬间” 或短暂的释放. $\mathrm{Zhu}{ }^{[219]}$ 通过一周的现场风浪与水体磷含量的观察和跟踪分析, 认为强风所引发的动力事件 导致了磷的爆发性释放, 进而推断动力释放可能是磷内源释放的主要方式. You 等 ${ }^{[56]}$ 将风的 “消退” 阶段也 放人以形成完整的风起风落闭合过程, 研究发现, 太湖磷酸盐和氨氮的释放通量在所有起风过程都发生明 显增加, 但在风的消退 (悬浮物沉降) 阶段, 水体含量 (释放通量) 很快减少; 消退至 $8 \mathrm{~h}$ 时, 水体磷酸盐、氨氮 和悬浮物含量基本恢复至风浪前初始水平 ${ }^{[160]}$, 提示大风猝发的沉积物释放仅有短暂的时效性. Wu 等 ${ }^{[220]}$ 研究了强风和弱风扰动下上覆水和沉积物中各形态氮含量的变化, 结果反映上覆水中的 $\mathrm{NH}_{4}^{+}$在强风浪下增 量 $\left(72 \mathrm{mg}\right.$ ) 是 $15 \mathrm{~cm}$ 深度间隙水中 $\mathrm{NH}_{4}^{+}$降幅 $(37.8 \mathrm{mg})$ 的近 2 倍, 强风浪引起沉积物一水界面的压力差是 $\mathrm{NH}_{4}^{+}$向上覆水扩散的主要原因. 郑杰文等 ${ }^{[35]}$ 经过研究总结, 风浪引起的沉积物一水界面物理失稳作用, 不应 只仅考虑波浪剪切力的“掀起” 作用, 实际除这种剪切破坏外, 还有液化破坏和液化一剪切破坏的震荡体运 动. Guo 等 ${ }^{[212]}$ 通过求解达西方程得到各向同性多孔沉积层的渗流场, 数值模拟了沉积物与上覆水孔隙水中 的非定常污染物溶质运移后认为, 上覆水流对界面的压力分布不均及波动性变化是增加污染物从沉积物向 上覆水体扩散的主要因素. 波浪一沉积物形貌的相互作用会使得像电子接受体类物质在沉积物中的传输更 为有效,Precht 等 ${ }^{[221]}$ 认为由波浪引起的溶质平流速率至少比扩散快 3 个数量级.

生物体在有限时空内的大量聚集或腐败, 对沉积物一水界面关键性污染物 “非常规” 行为的诱发作用也 被不断证实. Xie 等 ${ }^{[222]}$ 通过有/无沉积物的围隔研究微囊藻水华的形成对沉积物磷释放的可能影响, 结果表 明, 微囊藻水华通过强烈光合作用引起的高 $\mathrm{pH}$ 值, 形成对沉积物内磷的 “原吸” 作用, 或者说沉积物中磷因 藻华的形成发生了非主动性转化, 并在沉积物一水界面可能出现了反 Fick 第一定律的 “迁移”. 藻体对界面 的影响还不仅限于此, 在太湖和巢湖藻类易聚区, 夏秋季常可见沉积物表层被数毫米至数厘米厚度的藻席 (algal mat) 所覆盖, 在国外一些水域甚至发现过沉积物表层 $6 \sim 7 \mathrm{~cm}$ 内都有大量活性藻体 ${ }^{[31,223]}$. 以蛋白质、 多糖和似腐殖物质为主的水华微囊藻胞外聚合物, 与无机矿物为主具高吸附性沉积物的叠合和混杂, 会对 藻体形成物理损伤、窒息乃至死亡分解, 加速藻体无机化成为沉积物的一部分, 如果发生于较大的空间尺 度, 这一过程将会产生缓慢甚至突发性事件. 王亚荵等 ${ }^{[224]}$ 对藻体在沉积物一水界面的堆积效应研究表明, 在仅 $120 \mathrm{~g} / \mathrm{m}^{2}$ 的藻屑密度堆积下, 就可造成水体缺氧甚至戻氧, 继而导致氮、磷营养盐及溶解性有机物的大 量释放. 藻体和水草等生物质在局部湖区的长时间堆积还会出现一种称之为湖泛 (black bloom) 的水体黑臭 的突发性和极端性污染现象 ${ }^{[175]}$. 室内模拟表明 ${ }^{[185-186,225]}$, 湖泛的发生从藻体聚集开始到发生仅需要 $5 \mathrm{~d}$ 左 右, 水体变黑最先都是从近底泥表层上覆水开始的, 表明底泥强烈地参与了湖泛的发生过程. 蔡萍等 ${ }^{[226]}$ 用 沉积物+蓝藻、仅有沉积物和仅有蓝藻的 3 种处理, 模拟了太湖八房港湖泛发生的特征形态物质铁及硫含量 及黑度的变化, 发现沉积物+蓝藻处理中 $\mathrm{Fe}^{2+}$ 的浓度为仅蓝藻处理的 $11 \sim 94$ 倍, 还原性硫 $\left(\sum \mathrm{S}^{2-}=\mathrm{H}_{2} \mathrm{~S}, \mathrm{HS}^{-}\right.$, $\mathrm{S}^{2-}$ ) 浓度也为其他处理的 2 56 倍, 明显反映突发过程中沉积物通过界面向系统提供了发生湖泛的关键性 物质 $\left(\mathrm{Fe}^{2+}\right.$ 和 $\left.\Sigma \mathrm{S}^{2-}\right)$ 来源, 并形成藻源性的溶解性氮、磷及有机物的大量释放 ${ }^{[186,225]}$. 死亡水草在湖区的大量 和长时间堆积, 也同样会使沉积物一水界面发生高通量营养物释放, 申秋实等 ${ }^{[185]}$ 对 2012 年 5 月发生于太湖 贡湖湾的草源性湖泛再现模拟发现, 湖泛发生后沉积物的 $\mathrm{NH}_{4}^{+}-\mathrm{N} 、 \mathrm{SRP}$ 释放速率分别是对照区的 49.8 倍和 15.3 倍.

在湖泊的一些突发性污染事件中, 沉积物并不总是污染源, 可能扮演着 “汇”或在沉积物一水界面上对 污染物承担着“源一汇转换” 的功能,缓冲着湖泊污染程度和调剂污染物在介质中量的分配. 2007 年 9 月一 2008 年 10 月云南阳宗海水体砷含量从 $0 \sim 6 \mu \mathrm{g} / \mathrm{L}$ 急剧上升到 $134 \mu \mathrm{g} / \mathrm{L}$, 沉积物的总砷则高达 $54.9 \sim 193.3$ 
$\mathrm{mg} / \mathrm{kg}, 1$ 年后的 2009 年 9 月又降至平均约 $47.0 \mathrm{mg} / \mathrm{kg}$ 水平. 2010 年 4 月分析 $93 \%$ 的表层 $0 \sim 2 \mathrm{~cm}$ 沉积物中 As 含量超过我国土壤环境质量标准 (GB15618 - 1995) III 级标准限值 ( $30 \mathrm{mg} / \mathrm{kg}$ ), 其中 $39.9 \%$ 的形态 As 具 有可迁移性 ${ }^{[227]}$, 显然在阳宗海 As 污染事件中, 沉积物一水界面至少经历了一次 As 的汇一源转换过程, 对湖 水的 As 污染起到了缓冲作用. 如果沉积物系统中长期累积像重金属这样的污染物,当物化条件变化或环境 扰动, 而可能突然将污染物重新活化并释放造成水体的生态和环境危害, 形成所谓 “化学定时炸弹” “228-229]. Koval 等 ${ }^{[229]}$ 对贝加尔湖流域几个受人为和地质基岩 $\mathrm{Hg}$ 污染和异常赋存影响的 Bratsk 水库进行了沉积物调 查, 发现沉积物 $\mathrm{Hg}$ 含量在垂向剖面上中呈无规律分布的位置正是高技术污染场区, $\mathrm{Hg}$ 含量与沉积速率具 有较强的正相关性, 表层沉积物 $\mathrm{Hg}$ 含量 (30 6000 $\mu \mathrm{g} / \mathrm{kg}$ ) 远远大于周边河流沉积物 (平均 $21 \mu \mathrm{g} / \mathrm{kg}$ ), 已具 备形成 Hg 化学定时炸弹的条件. 沉积物一水界面缺氧是沉积物化学炸弹形成的主要条件之一. Banks 等 ${ }^{[230]}$ 对澳大利亚一受 $\mathrm{As} 、 \mathrm{Cd} 、 \mathrm{Cu}$ 和 $\mathrm{Zn}$ 高度污染的沉积物进行了 $40 \mathrm{~d}$ 耗氧过程的研究, 发现低氧期间沉积物通 过形成金属硫化物而将溶解的金属沉淀回沉积物中,使沉积物重金属含量持续增加. 这对水体的保护固然 好,但如果突发好氧事件(如山洪、特大风浪等)将很有可能使得重金属出现集中性释放. Roussiez ${ }^{[231]}$ 对沉积 物一水界面金属结合态分析发现, 沉积物中来自陆源的重金属有机配体的增加会使 $\mathrm{Cu}$ 逐渐转移到溶解相, $\mathrm{Pb}$ 和 $\mathrm{Zn}$ 与细沉积物具有较强的亲和力. 通过不稳定活性组分和残余组分的形成分析, 认为 $\mathrm{Cu} 、 \mathrm{~Pb}$ 和 $\mathrm{Zn}$ 是 沉积物中最不稳定重金属,最易受短暂和猛烈的山洪暴发的影响而对环境形成突发性污染.

\section{6 湖泊沉积物一水界面研究展望}

湖泊沉积物一水界面是理化性质的突变区、化学元素变化的敏感区和生物积极参与主要活动区, 界面上 化学物质的转化、循环、交换等过程异常活跃. 从已有的认识看, 几乎所有的湖泊水污染甚至生态问题都与 沉积物或沉积物一水界面有关, 几十年来人们在湖泊 (包括近海、河流、河口等) 沉积物一水界面过程的研究 中已开展了大量的工作,特别是近 20 年来取得了突飞猛进的研究进展. 从发展趋势展望, 该研究领域可继 续或加强以下几方面的研究:

1) 提升和完善沉积物一水界面信息获取技术应用和开发. 现有的被动采样和信息获取技术虽已基本达 到快速、高分辨、非破坏性、多维等一些特征, 但仍需在空间和时间分辨率上进一步完善, 在多组分、大容量 和易操作方面继续改进，同时还需更多地发展湖泊原位取样分析一体化、信息高频采集、信息远程传输、物 联网技术植人,使界面研究能在多位点或断面实行大范围内同步等. 现有的商业设备虽给予研究者极大的 支持, 但绝大多数是为满足监测和分析要求而制作的. 沉积物一水界面的问题很多且复杂, 仍需要研究者根 据具体情况来进行装备的研发. 在微观层面, Fick 第一定律所述的分子迁移有效扩散距离 $(Z)$ 至今还没有 令人信服的测量方法, 严重影响了界面分层尺度的选取和浓度梯度 (或释放速率) 的计算. 就国内而言, 与界 面湍流扩散有关的界面微小流体的测定和有生物席垫覆盖影响的研究还没有得到应有关注,高精度信息获 取技术对理论研究的支撑还有明显脱节; 沉积物的三维表征和断层扫描影像分析技术还未见有实质性开展 和技术应用. 此外, 有很多过程机理尚未得到合理解释, 也多是受限于所获信息的精细程度不足, 未来界面 信息获取技术的发展应更多地考虑服务于实际应用和过程机理的研究.

2) 加强沉积物一水界面物质交换定量化的精细度和可信性研究. 沉积物一水界面过程研究的主要产出 之一就是要以污染物通量、内源负荷和风险程度等数据和信息形式服务于实际应用. 在对污染湖泊治理前, 到底内源负荷的贡献份额多大往往是需要回答的问题. 我国的湖泊种类多, 特别是浅水湖生产力高、风浪作 用大, 影响因素较为复杂, 像“湖泛”、砷污染和藻华暴发这样一些与沉积物有关的新老问题需要解决, 这就 需要基于扎实的基础研究, 以可检验、可复制的高可信度要求将成果定量化服务于社会. 沉积物一水界面的 研究主要还是一项实验性科学, 属于实验湖沼学范畴. 无论原位和模拟都应逐步考虑湖泊的实际环境 (如物 理和生物扰动) 和人为影响因素 (疏浚和航线运输) 的影响. 目前已有的成果还主要关注的是氮磷营养物, 可 在完善氮磷定量化基础上,逐步关注相对复杂的重金属和 POPs 在沉积物一水界面的内源释放方面. 界面的 定量化工作还可从适合的内源释放通量估算方法选用、样品数量频次的时空完整性保证、满足统计学意义 的数据准确性分析等方面做进一步挖掘和完善.

3) 推进沉积物一水界面过程和效应研究模型的应用和构建. 沉积物一水界面过程研究中模型应用和构 
建仍是国际上重视的研究领域, 是探讨实际复杂环境中物质迁移转化的主要推荐方法. 很多沉积物一水界面 的问题需要借助模型的分析才有可能揭示物质的迁移转化机制. 比如沉积物的早期成岩在不同的有机质性 状和氧化还原环境中会有不同的物质参与反应; 沉积物界面上不同水力湍流作用和产生的界面压力差异会 使得表层沉积物发生剪切性扰动甚至近表层 “液化”, 造成水底边界层的有效扩散层厚度及溶质的迁移等发 生变化, 采用实验模拟是无法获得结果的. 另外在太湖、巢湖等一些湖区, 沉积物表层常会覆盖藻席, 内部还 有数量巨大的底栖生物掘穴和搬运等扰动作用, 这些都必须依赖于模型的概化等提升人们对沉积物一水界 面微观过程的认识, 以用费时费力的调查和实验是无能为力应对的. 此外还应加强沉积物一水界面的非物质 交换 (如热交换) 模型等方面的研究, 精细刻画和测量扩散边界层结构和尺度及其变化, 发掘界面附近物质能量流动间的关系, 为界面过程和机制的进一步揭示, 提供重要的基础理论和依据解释.

\section{7 参考文献}

[ 1 ] Hinderer M. Late Quaternary denudation of the Alps, valley and lake fillings and modern river loads. Geodinamica Acta, 2001, 14(4) : 231-263. DOI: 10.1080/09853111.2001.11432446.

[ 2 ] Leon JX, Cohen TJ. An improved bathymetric model for the modern and palaeo Lake Eyre. Geomorphology, 2012, 173/ 174: 69-79. DOI: 10.1016/j.geomorph.2012.05.029.

[ 3 ] Håkanson L, Jansson M eds. Lake sedimentology. New York: Springer-Veniag, 1983: 181-233.

[ 4 ] Lerman A. Chemical exchange across sediment-water interface. Annual Review of Earth and Planetary Sciences, 1978 , 6 (1) : 281-303. DOI: 10.1146/annurev.ea.06.050178.001433.

[ 5 ] Liu M, Xu SY, Hou LJ eds. Nutrients of sediment-water interface in tidal flat of the Yangtze estuary: Environmental biogeochemical processes. Beijing: Science Press, 2007: 3. [刘敏, 许世远, 侯立军. 长江口潮滩沉积物-水界面营养盐: 环境生物地球化学过程. 北京: 科学出版社, 2007: 3.]

[ 6 ] Fernex FE, Migon C, Chisholm JRM. Entrapment of pollutants in Mediterranean sediments and biogeochemical indicators of their impact. Hydrobiologia, 2001, 450(1/2/3) : 31-46. DOI: 10.1023/A:1017558413882.

[ 7 ] Fan CX, Zhou YY, Wu QL eds. The sediment-water interface of lakes: Processes and effects. Beijing: Science Press, 2013: 1-23, 198-206, 254-257, 302-341. [范成新, 周易勇, 吴庆龙. 湖泊沉积物界面过程与效应. 北京: 科学出版 社, 2013: 1-23, 198-206, 254-257, 302-341.]

[ 8 ] Wang SR ed. Sediment-water interface process of lakes: Nitrogen and phosphorus biogeochemistry. Beijing: Science Press, 2013: 1-9. [王圣瑞. 湖泊沉积物一水界面过程: 氮磷生物地球化学. 北京: 科学出版社, 2013: 1-9.]

[ 9 ] Søndergaard M, Jensen JP, Jeppesen E. Retention and internal loading of phosphorus in shallow, eutrophic lakes. The Scientific World Journal, 2001, 1: 427-442. DOI: 10.1100/tsw.2001.72.

[10] Duport E, Gilbert F, Poggiale JC et al. Benthic macrofauna and sediment reworking quantification in contrasted environments in the Thau Lagoon. Estuarine, Coastal and Shelf Science, 2007, 72(3) : 522-533. DOI: 10.1016/j. ecss.2006. 11.018 .

[11] Müller S, Mitrovic SM, Baldwin DS. Oxygen and dissolved organic carbon control release of N, P and Fe from the sediments of a shallow, polymictic lake. Journal of Soils and Sediments, 2016, 16(3) : 1109-1120. DOI: 10.1007/s11368015-1298-9.

[12] Carruthers RG. XIII.-the carboniferous sediments near Strathaven. Proceedings of the Geologists' Association, 1915, 26(3): 189-191. DOI: 10.1016/s0016-7878( 15 ) 80055-8.

[13] Mortimer CH. The exchange of dissolved substances between mud and water in lakes. The Journal of Ecology, 1941,29 (2) : 280-329. DOI: $10.2307 / 2256395$.

[14] Morita RY, ZøBell CE. Occurrence of bacteria in pelagic sediments collected during the mid-Pacific expedition. Deep Sea Research (1953), 1955, 3(1) : 66-73. DOI: 10.1016/0146-6313(55)90036-8.

[15] Goldberg ED, Arrhenius GOS. Chemistry of Pacific pelagic sediments. Geochimica et Cosmochimica Acta, 1958, 13 (2/) 3 ) : 153-212. DOI: 10.1016/0016-7037 ( 58 ) 90046-2.

[16] McCave IN ed. The benthic boundary layer. London: Plenum Press, 1976: 33-56, 261-272.

[17] Hayes FR, Reid BL, Cameron ML. Lake water and sediment. Limnology and Oceanography, 1958, 3(3) : 308-317. DOI: 10.4319/lo.1958.3.3.0308. 
[18] Wan GJ. Recent progress in environmental geochemistry of lakes. Environment and Sustainable Development, 1984, 9(7): 7-8. [万国江. 湖泊环境地球化学研究的最新进展. 环境科学动态, 1984, 9(7) : 7-8.]

[19] Hong JZ, Li L, Tang GP et al. Effects of nascent particiulate on the rate of Mn ( II ) oxidation near the seawater sediment interface. Journal of Xiamen University: Natural Science, 1987, 26(2) : 223-228. [洪家珍, 李莲, 汤谷平等. 海洋沉积 物一水界面邻近新生颗粒对 $\mathrm{Mn}$ ( II ) 氧化速度的影响. 厦门大学学报: 自然科学版, 1987, 26(2): 223-228.]

[20] Wu DS, Yuan ZQ, Huang RG et al. Development of a sampling device for sediment-water interface of lake. Chinese Journal of Environmental Engineering, 1988, 9(3): 62. [ 吴德殊, 袁自强, 黄荣贵等. 湖泊沉积物-水界面采样装置的研 制. 环境科学丛刊, 1988, 9(3):62.]

[21] Chen JM, Zhang WX, Liu TT et al. Scientometric analysis of papers published in 1989-2018 of Journal of Lake Sciences based on CiteSpace and CNKI database. J Lake Sci, 2019, 31(4) : 891-906. DOI: 10.18307/2019.0427. [陈俊梅, 张 文翔, 刘甜甜等. 基于 CiteSpace 和知网数据库的《湖泊科学》创刊 30 年( 1989-2018 年) 发表论文的文献计量学 分析. 湖泊科学, 2019, 31(4): 891-906.]

[22] Brown SL, Cox R, Feunteun E et al. Overview of the EUROSAM project and a decision support system. Continental Shelf Research, 2003, 23(17/18/19) : 1617-1634. DOI: 10.1016/j.csr.2003.06.007.

[23] Beylich AA, Etienne S, Etzelmüller B et al. The European science foundation ( ESF) network SEDIFLUX - an introduction and overview. Geomorphology, 2006, 80 (1/2) : 3-7. DOI: 10.1016/j.geomorph.2005.11.013.

[24] Barth JAC, Steidle D, Kuntz D et al. Deposition, persistence and turnover of pollutants : First results from the EU project AquaTerra for selected river basins and aquifers. Science of the Total Environment, 2007, 376(1/2/3) : 40-50. DOI: 10. 1016/j.scitotenv.2007.01.065.

[25] Duport E, Gilbert F, Poggiale JC et al. Benthic macrofauna and sediment reworking quantification in contrasted environments in the Thau Lagoon. Estuarine, Coastal and Shelf Science, 2007, 72(3) : 522-533. DOI: 10.1016/j. ecss.2006. 11.018 .

[26] Zhang ZN. Some progress of the study on the ecosystem dynamics for benthic-pelagic coupling. Journal of Ocean University of Qingdao, 2000, 30 (1) : 115-122. [张志南. 水层一底栖耦合生态动力学研究的某些进展. 青岛海洋大学学报: 自 然科学版, 2000, 30(1): 115-122.]

[27] Fan CX, Wang CX eds. Environmental geochemistry and eutrophication of lakes in the middle and lower reaches of the Yangtze River. Beijing: Science Press, 2007: 1-453. [范成新, 王春霞. 长江中下游湖泊环境地球化学与富营养化. 北京: 科学出版社, 2007: 1-453.]

[28] Jin XC, Wang SR, Chu JZ et al. Organic phosphorus in shallow lake sediments in middle and lower reaches of the Yangtze River area in China. Pedosphere, 2008, 18(3) : 394-400. DOI: 10.1016/s1002-0160(08)60030-2.

[29] Friedrichs M, Graf G, van Duren LA. Bio-fluid-dynamics: Exchange processes at the sediment-water interface. Journal of Sea Research, 2006, 55(1) : 1-2. DOI: 10.1016/j.seares.2005.10.008.

[30] Lerman A ed. Translated by Wang SM et al. Lakes: Chemistry geology physics. Beijing: Geological Publishing House, 1989: 1-307. [莱尔曼等编. 王苏民等译. 湖泊的化学地质学和物理学. 北京: 地质出版社, 1989: 1-370.]

[31] Boudreau BP, Jørgensen BB eds. The benthic boundary layer—transport processes and biogeochemistry. Oxford: Oxford University Press, 2001: 1-6, 78-97, 269-296.

[32] Boudreau BP, Jørgensen BB eds. Translated by Fan CX et al. The benthic boundary layer-transport processes and biogeochemistry. Beijing: Science Press, 2013: 57-62, 113-129, 161-220, 243-274.. [ (加)伯纳德・P. 布德罗，(德)布 · 巴克尔 . 约尔根森著. 范成新等译. 水底边界层: 迁移过程与生物地球化学. 北京: 科学出版社, 2013: 57-62, $113-129,161-220,243-274$. ]

[33] McClain CR, Huang NE, Pietrafesa LJ. Application of a “radiation-type” boundary condition to the wave, porous bed problem. Journal of Physical Oceanography, 1977, 7(6) : 823-835. DOI: 10.1175/1520-0485(1977) 0070823 : aoatbc> 2.0.co;2.

[34] Reed DC, Slomp CP, Gustafsson BG. Sedimentary phosphorus dynamics and the evolution of bottom-water hypoxia: A coupled benthic-pelagic model of a coastal system. Limnology and Oceanography, 2011, 56(3) : 1075-1092. DOI: 10. 4319/lo.2011.56.3.1075.

[35] Zheng JW, Jia YG, Liu XL et al. A review of the wave-induced sediment resuspension. Marine Geology \& Quaternary Geology, 2013, 33(5) : 173-183. [郑杰文, 贾永刚, 刘晓否等. 波浪作用下沉积物再悬浮过程研究进展. 海洋地质与 
第四纪地质, 2013, 33(5): 173-183.]

[36] Sun YF, Dong LF, Song YP. Analysis of characteristics and formation of disturbed soil on subaqueous delta of Yellow River. Rock and Soil Mechanics, 2008, 29(6) : 1494-1499. DOI: 10.16285/j.rsm.2008.06.030. [孙永福, 董立峰, 宋玉 鹏. 黄河水下三角洲粉质土扰动土层特征及成因探析. 岩土力学, 2008, 29(6) : 1494-1499.]

[37] Song CL, Cao XY, Li JQ et al. Contribution of phosphatase and microbial activity to endogenous load of phosphorus in lakes and its relation to eutrophication. Science in China Series D: Earth Sciences, 2005, 35(S2) : 90-100. [宋春雷, 曹 秀云, 李建秋等. 湖泊磷酸酶与微生物活性对内源磷负荷的贡献及其与富营养化的关系. 中国科学: D 辑: 地球 科学, 2005, 35(S2) : 90-100.]

[38] Wan GJ, Tang DG, Wu FC et al. New progress in carbon systems of sediment- water interface of lakes. Geology-geochemistry, 1996, 24(2) : 1-4. [万国江, 唐德贵, 吴丰昌等. 湖泊水一沉积物碳系统研究新进展. 地质地球化学, 1996, 24(2): 1-4.]

[39] Kong FX, Song LR eds. Study on the formation and environmental characteristics of Cyanobacteria blooms. Beijing: Science Press, 2011: 40-49. [ 孔繁翔, 宋立荣. 蓝藻水华形成过程及其环境特征研究. 北京: 科学出版社, 2011: 4049. ]

[40] Zhou QL, Liu C, Fan CX. Application of plow-tillage as an innovative technique for eliminating overwintering Cyanobacteria in eutrophic lake sediments. Environmental Pollution, 2016, 219: 425-431. DOI: 10.1016/j.envpol.2016.05.026.

[41] Teal LR, Bulling MT, Parker ER et al. Global patterns of bioturbation intensity and mixed depth of marine soft sediments. Aquatic Biology, 2008, 2(3) : 207-218. DOI: 10.3354/ab00052.

[42] Kristensen E, Penha-Lopes G, Delefosse M et al. What is bioturbation? The need for a precise definition for fauna in aquatic sciences. Marine Ecology Progress Series, 2012, 446: 285-302. DOI: 10.3354/meps09506.

[43] Cai W, Cai YJ, Gong ZJ et al. Temporal and spatial patterns of Corbicula fluminea in Lake Taihu. J Lake Sci, 2010,22 (5) : 714-722. DOI: 10.18307/2010.0513. [蔡炜, 蔡永久, 龚志军等. 太湖河蚬时空格局. 湖泊科学, 2010, 22 (5) : 714-722.]

[44] Cai YJ, Gong ZJ, Qin BQ. Community structure and diversity of macrozoobenthos in Lake Taihu, a large shallow eutrophic lake in China. Biodiversity Science, 2010, 18(1): 50-59. [蔡永久, 龚志军, 秦伯强. 太湖大型底栖动物群落结构及 多样性. 生物多样性, 2010, 18(1): 50-59.]

[45] Zhang L. Changes of sediment-water interface properties and phosphorus dynamics under bioturbation in lake [ Dissertation]. Nanjing: Nanjing Institute of Geography and Limnology, Chinese Academy of Sciences, 2010. [张雷. 生物扰动下 湖泊沉积物-水界面特征变化与磷的迁移转化 [学位论文]. 南京: 中国科学院南京地理与湖泊研究所, 2010.]

[46] Davison W, Zhang H. In situ speciation measurements of trace components in natural waters using thin-film gels. Nature, 1994, 367 (6463) : 546-548. DOI: 10.1038/367546a0.

[47] Zhang H, Davison W, Gadi R et al. In situ measurement of dissolved phosphorus in natural waters using DGT. Analytica Chimica Acta, 1998, 370(1) : 29-38. DOI: 10.1016/s0003-2670(98)00250-5.

[48] Ding SM, Xu D, Sun Q et al. Measurement of dissolved reactive phosphorus using the diffusive gradients in thin films technique with a high-capacity binding phase. Environmental Science \& Technology, 2010, 44(21) : 8169-8174. DOI: 10. $1021 /$ es1020873.

[49] Li HZ, You J. Advances in using passive sampling techniques to measure bioavailability and toxicity of organic contaminants in sediment. Chinese Journal of Chromatography, 2013, 31(7): 620-625. [李慧珍, 游静. 被动采样技术在测定 沉积物中有机污染物的生物可利用性和毒性中的研究进展. 色谱, 2013, 31(7) : 620-625.]

[50] König B, Kohls O, Holst G et al. Fabrication and test of sol-gel based planar oxygen optodes for use in aquatic sediments. Marine Chemistry, 2005, 97(3/4) : 262-276. DOI: 10.1016/j.marchem.2005.05.003.

[51] Tao YQ, Xue B, Yao SC. Using linoleic acid embedded cellulose acetate membranes to in situ monitor polycyclic aromatic hydrocarbons in lakes and predict their bioavailability to submerged macrophytes. Environmental Science \& Technology, 2015, 49(10): 6077-6084. DOI: 10.1021/acs.est.5b00863.

[52] Stahl H, Warnken KW, Sochaczewski L et al. A combined sensor for simultaneous high resolution 2-D imaging of oxygen and trace metals fluxes. Limnology and Oceanography: Methods, 2012, 10 (5): 389-401. DOI: 10.4319/lom. 2012. 10.389 .

[53] Zhang L, Shen QS, Hu HY et al. Impacts of Corbicula fluminea on oxygen uptake and nutrient fluxes across the sediment- 
water interface. Water, Air, \& Soil Pollution, 2011, 220(1/2/3/4) : 399-411. DOI: 10.1007/s11270-011-0763-3.

[54] Shen QS, Zhou QL, Shao SG et al. Estimation of in situ sediment nutrients release at the submerged plant induced black bloom area in Lake Taihu. J Lake Sci, 2014, 26(2) : 177-184. DOI: 10.18307/2014.0202. [ 申秋实, 周麒麟, 邵世光 等. 太湖草源性“湖泛”水域沉积物营养盐释放估算. 湖泊科学, 2014, 26(2) : 177-184.]

[55] Buchholtz-ten Brink MR, Gust G, Chavis D. Calibration and performance of a stirred benthic chamber. Deep Sea Research Part A Oceanographic Research Papers, 1989, 36(7) : 1083-1101. DOI: 10.1016/0198-0149(89)90079-4.

[56] You BS, Zhong JC, Fan CX et al. Effects of hydrodynamics processes on phosphorus fluxes from sediment in large, shallow Taihu Lake. Journal of Environmental Sciences, 2007, 19(9) : 1055-1060. DOI: 10.1016/S1001-0742(07)60172-7.

[57] Seeberg-Elverfeldt J, Schlüter M, Feseker T et al. Rhizon sampling of porewaters near the sediment-water interface of aquatic systems. Limnology and Oceanography: Methods, 2005, 3(8) : 361-371. DOI: 10.4319/lom.2005.3.361.

[58] Fan CX ed. Specifications for lake sediment survey. Beijing: Science Press, 2018: 102, 428-440. [范成新. 湖泊沉积物 调查规范. 北京: 科学出版社, 2018: 102, 428-440.]

[59] Hesslein RH. An in situ sampler for close interval pore water studies. Limnology and Oceanography, 1976, 21(6) : 912914. DOI: $10.4319 /$ lo.1976.21.6.0912

[60] Webster IT, Teasdale PR, Grigg NJ. Theoretical and experimental analysis of peeper equilibration dynamics. Environmental Science \& Technology, 1998, 32(11) : 1727-1733. DOI : 10.1021/es970815g.

[61] Wang JJ, Fan CX, Zhang L et al. Distribution characteristics and relativity of metal ions in the interstitial water of the bottom sludge in Lake Taihu. China Environmental Science, 2004, 24(1):120-124. [王建军, 范成新, 张路等. 太湖底泥 间隙水中金属离子分布特征及相关性. 中国环境科学, 2004, 24(1) : 120-124.]

[62] Zhang L, Fan CX, Wang JJ et al. Space-time dependent variances of ammonia and phosphorus flux on sediment-water interface in Lake Taihu. Environmental Science, 2006, 27(8): 1537-1543. DOI: 10.13227/j.hjkx.2006.08.011. [张路, 范成新, 王建军等. 太湖水土界面氮磷交换通量的时空差异. 环境科学, 2006, 27(8) : 1537-1543.]

[63] Xu D, Wu W, Ding SM et al. A high-resolution Dialysis technique for rapid determination of dissolved reactive phosphate and ferrous iron in pore water of sediments. Science of the Total Environment, 2012, 421/422: 245-252. DOI: 10.1016/j. scitotenv.2012.01.062.

[64] Davison W, Grime GW, Morgan JAW et al. Distribution of dissolved iron in sediment pore waters at submillimetre resolution. Nature, 1991, 352(6333) : 323-325. DOI: 10.1038/352323a0.

[65] Krom MD, Davison P, Zhang H et al. High-resolution pore-water sampling with a gel sampler. Limnology and Oceanography, 1994, 39(8) : 1967-1972. DOI: 10.4319/lo.1994.39.8.1967.

[66] Fones G, Davison W, Grime G. Development of constrained DET for measurements of dissolved iron in surface sediments at sub-mm resolution. Science of the Total Environment, 1998, 221 (2/3) : 127-137. DOI: 10.1016/s0048-9697 (98) 00273-3.

[67] Fan HT, Sun T, Sui DP et al. In-situ passive sampling techniques for environmental monitoring-diffusive equilibrium in thin-films and diffusive gradients in thin-films technique. Chemistry, 2009, 72(5): 421-426. [范洪涛, 孙挺, 隋殿鹏 等. 环境监测中两种原位被动采样技术一一薄膜扩散平衡技术和薄膜扩散梯度技术. 化学通报, 2009, 72(5): 421-426.]

[68 ] Zhang H, Davison W. Performance characteristics of diffusion gradients in thin films for the in situ measurement of trace metals in aqueous solution. Analytical Chemistry, 1995, 67(19) : 3391-3400. DOI: 10.1021/ac00115a005.

[69] Naylor C, Davison W, Motelicaheino M et al. Simultaneous release of sulfide with Fe, Mn, Ni and Zn in marine harbour sediment measured using a combined metal/sulfide DGT probe. Science of the Total Environment, 2004, 328(1/2/3): 275-286. DOI: $10.1016 /$ j.scitotenv.2004.02.008.

[70] Luo J, Wang JF, Yang HQ et al. Progress in research on in-situ monitoring technology for determining the phosphate contents of sediment pore water. Earth and Environment, 2014, 42(5): 688-694. [罗婧, 王敬富, 杨海全等. 湖泊沉积物 孔隙水磷酸盐含量原位监测技术研究进展. 地球与环境, 2014, 42(5): 688-694.]

[71] Teasdale PR, Hayward S, Davison W. In situ, high-resolution measurement of dissolved sulfide using diffusive gradients in thin films with computer-imaging densitometry. Analytical Chemistry, 1999, 71 ( 11 ): 2186-2191. DOI: 10. 1021/ac981329u.

[72] DeVries CR, Wang FY. In situ two-dimensional high-resolution profiling of sulfide in sediment interstitial waters. Environ- 
mental Science \& Technology, 2003, 37(4) : 792-797. DOI: 10.1021/es026109j.

[73] Sui DP, Sun T, Fan HT et al. Diffusive gradients in thin-films technique-A technique for in situ sampling. Chemistry, 2007, 70(12) : 954-960. [ 隋殿鹏, 孙挺, 范洪涛等. 薄膜扩散梯度技术一一种原位富集采样技术. 化学通报, $2007,70(12): 954-960$.

[74] Stockdale A, Davision W, Zhang H. High-resolution two-dimensional quantitative analysis of phosphorus, vanadium and arsenic, and qualitative analysis of sulfide, in a freshwater sediment. Environmental Chemistry, 2008, 5(2) : 143-149.

[75] Huynh T, Zhang H, Noller B. Evaluation and application of the diffusive gradients in thin films technique using a mixedbinding gel layer for measuring inorganic arsenic and metals in mining impacted water and soil. Analytical Chemistry, 2012, 84(22) : 9988-9995. DOI: 10.1021/ac302430b.

[76] Ding SM, Sun Q, Xu D et al. High-resolution simultaneous measurements of dissolved reactive phosphorus and dissolved sulfide: The first observation of their simultaneous release in sediments. Environmental Science \& Technology, 2012,46 (15) : 8297-8304.

[77] Jonker MTO, van der Heijden SA, Adelman D et al. Advancing the use of passive sampling in risk assessment and management of sediments contaminated with hydrophobic organic chemicals: results of an international ex situ passive sampling interlaboratory comparison. Environmental Science \& Technology, 2018, 52 (6) : 3574-3582. DOI: 10. 1021/acs. est.7b05752.

[78] Tao YQ, Xue B, Yao SC et al. Triolein embedded cellulose acetate membrane as a tool to evaluate sequestration of PAHs in lake sediment core at large temporal scale. Environmental Science \& Technology, 2012, 46(7) : 3851-3858. DOI: 10. 1021/es203102b.

[79] Tao YQ, Xue B, Yao SC. Using linoleic acid embedded cellulose acetate membranes to in situ monitor polycyclic aromatic hydrocarbons in lakes and predict their bioavailability to submerged macrophytes. Environmental Science \& Technology, 2015, 49(10) : 6077-6084. DOI: 10.1021/acs.est.5b00863.

[80] Bao LJ, Zeng EY. Application of passive sampling techniques in measurement of HOCs in aquatic environments//Zeng EY ed. Persistent organic pollutants (POPs): Analytical techniques, environmental fate and biological effects. Amsterdam: Elsevier, 2015: 135-159.

[81] Lin D, Eek E, Oen A et al. Novel probe for in situ measurement of freely dissolved aqueous concentration profiles of hydrophobic organic contaminants at the sediment-water interface. Environmental Science \& Technology Letters, 2015, 2(11): 320-324. DOI: 10.1021/acs.estlett.5b00239.

[82] Khairy MA, Lohmann R. Using polyethylene passive samplers to study the partitioning and fluxes of polybrominated diphenyl ethers in an urban river. Environmental Science \& Technology, 2017, 51(16) : 9062-9071. DOI: 10.1021/acs. est.7b02418.

[83] Cole RF, Mills GA, Hale MS et al. Development and evaluation of a new diffusive gradients in thin-films technique for measuring organotin compounds in coastal sediment pore water. Talanta, 2018, 178: 670-678. DOI: 10.1016/j.talanta. 2017.09.081.

[84] Yuan ZF, Gustave W, Bridge J et al. Tracing the dynamic changes of element profiles by novel soil porewater samplers with ultralow disturbance to soil-water interface. Environmental Science \& Technology, 2019, 53(9) : 5124-5132. DOI: 10. 1021/acs.est.8b05390.

[85] Wang SR ed. Sediment-water interface process of lakes: Basic theory and commonly used measuring methods. Beijing: Science Press, 2014: 225-248, 282. [王圣瑞. 湖泊沉积物-水界面过程: 基本理论与常用测定方法. 北京: 科学出版 社, 2014: 225-248, 282.]

[86] Santner J, Zhang H, Leitner D et al. High-resolution chemical imaging of labile phosphorus in the rhizosphere of Brassica napus L. cultivars. Environmental and Experimental Botany, 2012, 77: 219-226. DOI: 10. 1016/j. envexpbot. 2011. 11.026.

[87] Gundersen JK, Jorgensen BB. Microstructure of diffusive boundary layers and the oxygen uptake of the sea floor. Nature, 1990, 345(6276) : 604-607. DOI: 10.1038/345604a0.

[88] Stahl H, Glud A, Schröder CR et al. Time-resolved pH imaging in marine sediments with a luminescent planar optode. Limnology and Oceanography: Methods, 2006, 4(10): 336-345.

[89] Han C, Yao L, Xu D et al. High-resolution imaging of $\mathrm{pH}$ in alkaline sediments and water based on a new rapid response 
fluorescent planar optode. Scientific Reports, 2016, 6: 26417. DOI: 10.1038/srep26417.

[90] Han C, Ren JH, Tang H et al. Quantitative imaging of radial oxygen loss from Valisneria spiralis roots with a fluorescent planar optode. Science of the Total Environment, 2016, 569/570: 1232-1240. DOI: 10.1016/j.scitotenv.2016.06.198.

[91] Bennett WW, Teasdale PR, Welsh DT et al. Optimization of colorimetric DET technique for the in situ, two-dimensional measurement of iron( II ) distributions in sediment porewaters. Talanta, 2012, 88: 490-495. DOI: 10. 1016/j. talanta. 2011.11.020.

[92] Xu D, Chen YF, Ding SM et al. Diffusive gradients in thin films technique equipped with a mixed binding gel for simultaneous measurements of dissolved reactive phosphorus and dissolved iron. Environmental Science \& Technology, 2013,47 (18) : 10477-10484. DOI: 10.1021/es401822x.

[93] Cesbron F, Metzger E, Launeau P et al. Simultaneous 2D imaging of dissolved iron and reactive phosphorus in sediment porewaters by thin-film and hyperspectral methods. Environmental Science \& Technology, 2014, 48(5) : 2816-2826. DOI: $10.1021 / \mathrm{es} 404724 \mathrm{r}$.

[94] Gao Y, van de Velde S, Williams PN et al. Two-dimensional images of dissolved sulfide and metals in anoxic sediments by a novel diffusive gradients in thin film probe and optical scanning techniques. TrAC Trends in Analytical Chemistry, 2015, 66: 63-71. DOI: 10.1016/j.trac.2014.11.012.

[95] Wang SR, Wu ZH, Luo J. Transfer mechanism, uptake kinetic process, and bioavailability of P, Cu, Cd, Pb, and Zn in macrophyte rhizosphere using diffusive gradients in thin films. Environmental Science \& Technology, 2018, 52(3) : 10961108. DOI: $10.1021 /$ acs.est.7b01578.

[96] Wang SR, Wu ZH. The basic theory of P-process at sediment/water interface (SWI) in lake. DGT-based measurement of phosphorus in sediment microzones and rhizospheres. Singapore: Springer Singapore, 2016: 3-25. DOI: 10. 1007/978981-10-0721-7_1

[97] Meysman F, Middelburg J, Heip C. Bioturbation: a fresh look at Darwin's last idea. Trends in Ecology \& Evolution, 2006, 21(12) : 688-695. DOI: 10.1016/j.tree.2006.08.002.

[98] Maire O, Lecroart P, Meysman F et al. Quantification of sediment reworking rates in bioturbation research: A review. Aquatic Biology, 2008, 2(3) : 219-238. DOI: 10.3354/ab00053.

[99] Ouellette D, Desrosiers G, Gagne JP et al. Effects of temperature on in vitro sediment reworking processes by a gallery biodiffusor, the polychaete Neanthes virens. Marine Ecology Progress Series, 2004, 266: 185-193. DOI: 10. 3354/ meps266185.

[100] Shull DH. Bioturbation//John HS, Karl KT, Steve AT eds. Encyclopedia of ocean sciences. Oxford: Academic Press, 2009: 3513-3518

[101] Wang YG, Wang ZR. Study on the intensity and characteristics of bioturbation in branching Bay - Taking shanhaiguan dashihe branching bay as an example. Journal of Ocean University of Qingdao, 1999, 29(4) : 709-714. [王英国, 王珍 如. 河口湾区生物扰动强度及扰动作用特征研究——山海关大石河河口湾为例. 青岛海洋大学学报: 自然科学 版, 1999, 29(4) : 709-714.]

[102] D'Andrea AF, DeWitt TH. Geochemical ecosystem engineering by the mud shrimp Upogebia pugettensis (Crustacea: Thalassinidae) in Yaquina Bay, Oregon: Density-dependent effects on organic matter remineralization and nutrient cycling. Limnology and Oceanography, 2009, 54(6) : 1911-1932. DOI: 10.4319/lo.2009.54.6.1911.

[103] Sandnes J, Forbes T, Hansen R et al. Influence of particle type and faunal activity on mixing of di(2-ethylhexyl) phthalate (DEHP) in natural sediments. Marine Ecology Progress Series, 2000, 197: 151-167. DOI: 10.3354/meps197151.

[104] Blair NE, Levin LA, DeMaster DJ et al. The short-term fate of fresh algal carbon in continental slope sediments. Limnology and Oceanography, 1996, 41(6) : 1208-1219. DOI: 10.4319/lo.1996.41.6.1208.

[105] Fan DJ, Xu L, Qi HY. Bioturbation in surficial sediments of subaqueous changiiang (Yangtze) river delta. Oceanologia et Limnologia Sinica, 2008, 39(6): 577-584. [范德江, 徐琳, 齐红艳. 长江水下三角洲浅表沉积层中的生物扰动构 造. 海洋与湖沼, $2008,39(6): 577-584$.

[106] Solan M, Wigham BD, Hudson IR et al. In situ quantification of bioturbation using time-lapse fluorescent sediment profile imaging (f-SPI), luminophore tracers and model simulation. Marine Ecology Progress Series, 2004, 271: 1-12. DOI: 10. 3354/meps271001.

[107] Gilbert F, Hulth S, Grossi V et al. Redox oscillation and benthic nitrogen mineralization within burrowed sediments: An 
experimental simulation at low frequency. Journal of Experimental Marine Biology and Ecology, 2016, 482 : 75-84. DOI: 10.1016/j.jembe.2016.05.003.

[108] Zeng LX, Luo GJ, He TR et al. Effects of sulfate-reducing bacteria on methylmercury at the sediment-water interface. Journal of Environmental Sciences, 2016, 46: 214-219. DOI: 10.1016/j.jes.2016.05.018.

[109] L'Helguen S, Chauvaud L, Cuet P et al. A novel approach using the $15 \mathrm{~N}$ tracer technique and benthic chambers to determine ammonium fluxes at the sediment-water interface and its application in a back-reef zone on Reunion Island (Indian Ocean). Journal of Experimental Marine Biology and Ecology, 2014, 452: 143-151. DOI: 10.1016/j.jembe.2013.12.001.

[110] Xue JY, Jiang XY, Yao XL. Dissimilatory nitrate reduction processes at the sediment-water interface in Lake Kuilei. China Environmental Science, 2018, 38(6) : 2289-2296. [薛惊雅, 姜星宇, 姚晓龙等. 傀儡湖沉积物-水界面硝酸盐异养还 原过程研究. 中国环境科学, 2018, 38(6): 2289-2296.]

[111] Liu HH, Bao LJ, Zeng EY. Recent advances in the field measurement of the diffusion flux of hydrophobic organic chemicals at the sediment-water interface. TrAC Trends in Analytical Chemistry, 2014, 54: 56-64. DOI: 10.1016/j.trac.2013. 11.005 .

[112] Du YH, Liu C, Chen KN et al. Occurrence and internal loadings of nitrogen and phosphorus in the sediment of Lake Baiyangdian. J Lake Sci, 2018, 30(6) : 1537-1551. DOI : 10.18307/2018.0606. [杜奕衡, 刘成, 陈开宁等. 白洋淀沉积 物氮磷赋存特征及其内源负荷. 湖泊科学, 2018, 30(6) : 1537-1551.]

[113] Ciceri G, Maran C, Martinotti W et al. Geochemical cycling of heavy metals in a marine coastal area: benthic flux determination from pore water profiles and in situ measurements using benthic chambers. Hydrobiologia, 1992, 235/236(1): 501-517. DOI: 10.1007/BF00026238.

[114] Yang LY, Choi JH, Hur J. Benthic flux of dissolved organic matter from lake sediment at different redox conditions and the possible effects of biogeochemical processes. Water Research, 2014, 61 : 97-107. DOI: 10.1016/j.watres.2014.05.009.

[115] Buchholtz-ten Brink MR, Gust G, Chavis D. Calibration and performance of a stirred benthic chamber. Deep Sea Research Part a Oceanographic Research Papers, 1989, 36(7) : 1083-1101. DOI: 10.1016/0198-0149(89)90079-4.

[116] Zaaboub N, Ounis A, Helali MA et al. Phosphorus speciation in sediments and assessment of nutrient exchange at the water-sediment interface in a Mediterranean lagoon: Implications for management and restoration. Ecological Engineering, 2014, 73: 115-125. DOI: 10.1016/j.ecoleng.2014.09.017.

[117] Zhang L, Shang JG, He W et al. The role of tubificid worms (Limnodrilus hoffmeisteri) in sediment resuspension: A microcosm study. Annales de Limnologie-International Journal of Limnology, 2014, 50 ( 3 ) : 253-260. DOI: 10. 1051/ $\operatorname{limn} / 2014013$

[118] Williams GP. Aids in designing laboratory flumes. Washington, DC: Open file report, U.S. Geological Survey, 1971.

[119] Muschenheim DK, Grant J, Mills EL. Flumes for benthic ecologists: theory, construction and practice. Marine Ecology Progress Series, 1986, 28: 185-196. DOI: 10.3354/meps028185.

[120] House WA, Denison FH, Smith JT et al. An investigation of the effects of water velocity on inorganic phosphorus influx to a sediment. Environmental Pollution, 1995, 89(3) : 263-271. DOI: 10.1016/0269-7491(94)00071-k.

[121] Henderson FM ed. Open channel flow. MacMillan, New York, 1996.

[122] Zhu GW, Qin BQ, Zhang L et al. Wave effects on nutrient release of sediments from Lake Taihu by flume experiments. $J$ Lake Sci, 2005, 17(1): 61-68. DOI: 10.18307/2005.0110. [ 朱广伟, 秦伯强, 张路等. 太湖底泥悬浮中营养盐释放 的波浪水槽试验. 湖泊科学, 2005, 17(1): 61-68.]

[123] Huang JZ, Ge XP, Wang DS. Distribution of heavy metals in the water column, suspended particulate matters and the sediment under hydrodynamic conditions using an annular flume. Journal of Environmental Sciences, 2012, 24(12) : 20512059. DOI: 10.1016/s1001-0742(11)61042-5.

[124] Wu D, Hua ZL. The effect of vegetation on sediment resuspension and phosphorus release under hydrodynamic disturbance in shallow lakes. Ecological Engineering, 2014, 69: 55-62. DOI: 10.1016/j.ecoleng.2014.03.059.

[125] Lei Y, Wang PF, Wang C et al. The effect of submerged plants on the release of heavy metal from sediment under different hydrodynamic disturbances. Chinese Journal of Hydrodynamics, 2015, 30(3) : 245-250. [雷阳, 王沛芳, 王超等. 不同 水动力扰动下沉水植物对沉积物重金属释放的影响. 水动力学研究与进展 A 辑, 2015, 30(3): 245-250.]

[126] Xie MW, Jarrett BA, da Silva-Cadoux C et al. Coupled effects of hydrodynamics and biogeochemistry on Zn mobility and speciation in highly contaminated sediments. Environmental Science \& Technology, 2015, 49(9) : 5346-5353. DOI: 10. 
1021/acs.est.5b00416.

[127] Li YP, Wang Y, Anim DO et al. Flow characteristics in different densities of submerged flexible vegetation from an openchannel flume study of artificial plants. Geomorphology, 2014, 204: 314-324. DOI: 10.1016/j.geomorph.2013.08.015.

[128] Hua ZL, Wang Y. Advance on the release of pollutants in river and lake sediments under hydrodynamic conditions. Journal of Hohai University: Natural Sciences, 2018, 46(2) : 95-105. [华祖林, 王苑. 水动力作用下河湖沉积物污染物释放 研究进展. 河海大学学报: 自然科学版, 2018, 46(2): 95-105.]

[129] Søndergaard M, Kristensen P, Jeppesen E. Phosphorus release from resuspended sediment in the shallow and wind-exposed Lake Arres $\varnothing$, Denmark. Hydrobiologia, 1992, 228(1) : 91-99. DOI: 10.1007/bf00006480.

[130] Fan CX. A method and device for indoor simulation of resuspension of underwater sediments. ZL 200410014329.X F15D. 2006-09-27. [范成新. 一种室内模拟水下沉积物再悬浮状态的方法及装置. ZL 200410014329.X - F15D. 2006-09-27.]

[131] You BS, Wang TC, Fan CX et al. Quantitative simulative method of sediment resuspension in Lake Taihu. J Lake Sci, 2007, 19(5) : 611-617. DOI: 10.18307/2007.0518. [尤本胜, 王同成, 范成新等. 太湖沉积物再悬浮模拟方法. 湖 泊科学, 2007, 19(5): 611-617.]

[132] Ha HK, Maa JPY, Park K et al. Estimation of high-resolution sediment concentration profiles in bottom boundary layer using pulse-coherent acoustic Doppler current profilers. Marine Geology, 2011, 279(1/2/3/4) : 199-209. DOI: 10.1016/j. margeo.2010.11.002.

[133] Wang ZS, Wang SH, Zhang ZN et al. Studies on the genetic diversity of marine organisms: A review. Journal of Ocean University of Qingdao, 1999, 29(2) : 279-282. [于子山, 王诗红, 张志南等. 紫彩血蛤的生物扰动对沉积物颗粒垂直 分布的影响. 青岛海洋大学学报: 自然科学版, 1999, 29(2): 279-282.]

[134] Sun G, Fang Y, Wang P et al. Bioturbation effects of Branchiura sowerbyi (Tubificidae) on the vertical transport of sedimentary particles in paddy field. Agricultural Science \& Technology, 2010, 11(8): 117-119. [孙刚, 房岩, 王平等. 颤 蚓对水田沉积物颗粒垂直运移的生物扰动效应. 农业科学与技术: 英文版, 2010, 11(8): 117-119.]

[135] Matsui GY, Volkenborn N, Polerecky L et al. Mechanical imitation of bidirectional bioadvection in aquatic sediments. Limnology and Oceanography: Methods, 2011, 9(3) : 84-96. DOI: 10.4319/lom.2011.9.84.

[136] Gerino M, Stora G, François CF et al. Macro-invertebrate functional groups in freshwater and marine sediments: a common mechanistic classification. Vie et Milieu, 2003, 53: 221-232.

[137] Bernard G, Gammal J, Järnström M et al. Quantifying bioturbation across coastal seascapes: Habitat characteristics modify effects of macrofaunal communities. Journal of Sea Research, 2019, 152: 101766. DOI: 10.1016/j.seares.2019.101766.

[138] Jensen HS, Kristensen P, Jeppesen E et al. Iron: phosphorus ratio in surface sediment as an indicator of phosphate release from aerobic sediments in shallow lakes. Hydrobiologia , 1992, 235/236(1) : 731-743. DOI: 10.1007/bf00026261.

[139] Reddy KR, Fisher MM, Ivanoff D. Resuspension and diffusive flux of nitrogen and phosphorus in a hypereutrophic lake. Journal of Environment Quality, 1996, 25(2) : 363. DOI: 10.2134/jeq1996.00472425002500020022x.

[140] Fan CX, Zhang L, Qin BQ et al. Estimation on dynamic release of phosphorus from wind-induced suspended particulate matter in Lake Taihu. Science in China Series D, 2004, 47(8) : 710-719. DOI: 10.1360/02yd0184.

[141] Wang S, Jin X, Bu Q et al. Effects of particle size, organic matter and ionic strength on the phosphate sorption in different trophic lake sediments. Journal of Hazardous Materials, 2006, 128 (2/3) : 95-105. DOI: 10. 1016/j. jhazmat. 2005. 07.048 .

[142] Frindte K, Allgaier M, Grossart HP et al. Redox stability regulates community structure of active microbes at the sedimentwater interface. Environmental Microbiology Reports, 2016, 8(5) : 798-804. DOI: 10.1111/1758-2229.12441.

[143] Song CL, Cao XY, Zhou YY et al. Nutrient regeneration mediated by extracellular enzymes in water column and interstitial water through a microcosm experiment. Science of the Total Environment, 2019, 670: 982-992. DOI: 10.1016/j.scitotenv. 2019.03.297.

[144] Hupfer M, Lewandowski J. Oxygen controls the phosphorus release from lake sediments - a long-lasting paradigm in limnology. International Review of Hydrobiology, 2008, 93(4/5) : 415-432. DOI: 10.1002/iroh.200711054.

[145] Lei P, Zhang H, Wang C et al. Migration and diffusion for pollutants across the sediment-water interface in lakes: A review. J Lake Sci, 2018, 30(6) : 1489-1508. DOI: 10.18307/2018.0602. [雷沛, 张洪, 王超等. 沉积物-水界面污染物 迁移扩散的研究进展. 湖泊科学, 2018, 30(6) : 1489-1508.] 
[146] Song JM ed. Chemistry of sediment-seawater interface of the China Seas. Beijing: Ocean Press, 1997. [ 宋金明. 中国近 海沉积物-海水界面化学. 北京: 海洋出版社, 1997.]

[147] Chen Q, Chen JG, Wang JF et al. In situ, high-resolution evidence of phosphorus release from sediments controlled by the reductive dissolution of iron-bound phosphorus in a deep reservoir, southwestern China. Science of the Total Environment, 2019, 666: 39-45. DOI: 10.1016/j.scitotenv.2019.02.194.

[148] Yu S, Li HB. Perspectives on the release of heavy metals via sediment resuspension. Ecology and Environmental Sciences, 2010, 19(7) : 1724-1731. [俞慎, 历红波. 沉积物再悬浮-重金属释放机制研究进展. 生态环境学报, 2010,19 (7) : 1724-1731.]

[149] Dai GH, Liu XH. Factors affacting the migration of persistent organic pollutants across the sediment-water interface of aquatic environment. Environmental Chemistry, 2011, 30(1): 224-230. [戴国华, 刘新会. 影响沉积物-水界面持久性 有机污染物迁移行为的因素研究. 环境化学, 2011, 30(1): 224-230.]

[150] Rydin E. Potentially mobile phosphorus in Lake Erken sediment. Water Research, 2000, 34(7) : 2037-2042. DOI: 10. 1016/s0043-1354(99)00375-9.

[151] Li QM, Zhang W, Wang XX et al. Phosphorus in interstitial water induced by redox potential in sediment of Dianchi Lake, China. Pedosphere, 2007, 17(6) : 739-746. DOI: 10.1016/S1002-0160(07)60089-7.

[152] Gong MD, Jin ZF, Wang Y et al. Coupling between iron and phosphorus in sediments of shallow lakes in the middle and lower reaches of Yangtze River using diffusive gradients in thin films (DGT). J Lake Sci, 2017, 29(5) : 1103-1111. DOI: 10.18307/2017.0508. [龚梦丹, 金增锋, 王燕等. 长江中下游典型浅水湖泊沉积物一水界面磷与铁的耦合关系. 湖 泊科学, $2017,29(5)$ : 1103-1111.]

[153] Valdemarsen T, Quintana CO, Flindt MR et al. Organic N and P in eutrophic fjord sediments-rates of mineralization and consequences for internal nutrient loading. Biogeosciences, 2015, 12(6) : 1765-1779. DOI: 10.5194/bg-12-1765-2015.

[154] Zhao HC, Zhang L, Wang SR et al. Features and influencing factors of nitrogen and phosphorus diffusive fluxes at the sediment-water interface of Erhai Lake. Environmental Science and Pollution Research, 2018, 25(2) : 1933-1942. DOI: 10. 1007/s11356-017-0556-3.

[155] Satoh H, Okabe S. Spatial and temporal oxygen dynamics in macrofaunal burrows in sediments: A review of analytical tools and observational evidence. Microbes and Environments, 2013, 28(2) : 166-179. DOI: 10.1264/jsme2.me12182.

[156] Zhong DS, Wang F, Wang CS et al. Effect on the bioturbation of carps in different density on denitrification, nitrification and nitrate ammonification rates on sediment-water interface. Acta Hydrobiologica Sinica, 2013, 37(6) : 1103-1111. DOI: 10.7541/2013.149. [钟大森, 王芳, 王春生等. 不同密度下的鲤鱼扰动作用对沉积物-水界面硝化、反硝化和氨化 速率的影响. 水生生物学报, 2013, 37(6) : 1103-1111.]

[157] Wu D, Hua ZL. The effect of vegetation on sediment resuspension and phosphorus release under hydrodynamic disturbance in shallow lakes. Ecological Engineering, 2014, 69: 55-62. DOI: 10.1016/j.ecoleng.2014.03.059.

[158] Haese RR, Hensen C, de Lange GJ. Pore water geochemistry of Eastern Mediterranean mud volcanoes: Implications for fluid transport and fluid origin. Marine Geology, 2006, 225(1/2/3/4) : 191-208. DOI: 10.1016/j.margeo.2005.09.001.

[159] Yang YQ, Liu L, Chen MS et al. Effect of chironomid larvae bioturbation on release of internal phosphorus in eutrophic lake. Journal of Hohai University: Natural Sciences, 2016, 44(6) : 485-490. [杨艳青, 刘凌, 陈沐松等. 摇蚊幼虫生物 扰动对富营养化湖泊内源磷释放的影响. 河海大学学报:自然科学版, 2016, 44(6): 485-490.]

[160] You BS, Wang TC, Fan CX et al. The simulation of ammonia nitrogen and phosphorus loading variations under the influence of wind-wave in aquatic macrophytes areas of Lake Taihu. China Environmental Science, 2008, 28(1): 33-38. [尤 本胜, 王同成, 范成新等. 风浪作用下太湖草型湖区水体 $N 、 P$ 动态负荷模拟. 中国环境科学, 2008, 28(1): 33-38.]

[161] Wang JJ, Pang Y, Li YP et al. Experimental study of wind-induced sediment suspension and nutrient release in Meiliang Bay of Lake Taihu, China. Environmental Science and Pollution Research, 2015, 22(14) : 10471-10479. DOI: 10.1007/ s11356-015-4247-7.

[162] Benoit JM, Shull DH, Harvey RM et al. Effect of bioirrigation on sediment-water exchange of methylmercury in Boston Harbor, Massachusetts. Environmental Science \& Technology, 2009, 43 (10) : 3669-3674. DOI: 10.1021/es803552q.

[163] Yan CZ, Zeng LQ, Che FF et al. High-resolution characterization of arsenic mobility and its correlation to labile iron and manganese in sediments of a shallow eutrophic lake in China. Journal of Soils and Sediments, 2018, 18(5) : 2093-2106. 
DOI : $10.1007 / \mathrm{s} 11368-018-1929-z$.

[164] Hupfer M, Lewandowski J. Retention and early diagenetic transformation of phosphorus in Lake Arendsee ( Germany) -consequences for management strategies. Archiv für Hydrobiologie, 2005, 164 (2) : 143-167. DOI: 10.1127/0003-9136/ 2005/0164-0143.

[165] Xie MW, Jarrett BA, da Silva-Cadoux C et al. Coupled effects of hydrodynamics and biogeochemistry on Zn mobility and speciation in highly contaminated sediments. Environmental Science \& Technology, 2015, 49(9) : 5346-5353. DOI: 10. 1021/acs.est.5b00416.

[166] Burgess RM, Kester DR. Release and phase partitioning of metals from anoxic estuarine sediments during periods of simulated resuspension. Environmental Science \& Technology, 2002, 36(24) : 5328-5334. DOI: 10.1021/es0115058.

[167] Zhou YY, Song CL, Cao XY et al. Phosphorus fractions and alkaline phosphatase activity in sediments of a large eutrophic Chinese lake (Lake Taihu). Hydrobiologia, 2008, 599(1) : 119-125. DOI: 10.1007/s10750-007-9185-z.

[168] Zhu JS, Gao RX, Wang YM et al. The diffusion flux of mercury at water/sediment interface in water-level-fluctuating zone of the three gorges reservoir. Earth and Environment, 2018, 46(2): 164-172. [朱金山, 高润霞, 王永敏等. 三峡库区 消落带沉积物-水界面采的扩散特征. 地球与环境, 2018, 46(2) : 164-172.]

[169] Zeng LX, Luo GJ, He TR et al. Effects of sulfate-reducing Bacteria on methylmercury at the sediment-water interface. Journal of Environmental Sciences, 2016, 46: 214-219. DOI: 10.1016/j.jes.2016.05.018.

[170] Chen L, Zhang JJ, Zheng XL. A laboratory study of the presence and transformation of dissolved Mn(III) across the sediment-water interface of an anoxic freshwater body. Environmental Earth Sciences, 2019, 78(4): 108. DOI: 10.1007/ s12665-019-8113-7.

[171] Fan XF, Ding SM, Chen MS et al. Mobility of chromium in sediments dominated by macrophytes and Cyanobacteria in different zones of Lake Taihu. Science of the Total Environment, 2019, 666: 994-1002. DOI: 10.1016/j. scitotenv. 2019. 02.299 .

[172] He Y, Men B, Yang XF et al. Bioturbation effect on the migration and transformation of heavy metals in sediment: A review. Asian Journal of Ecotoxicology, 2016, 11(6): 25-36. [何怡, 门涁, 杨晓芳等. 生物扰动对沉积物中重金属迁 移转化影响的研究进展. 生态毒理学报, 2016, 11(6) : 25-36.]

[173] Zhang WQ, Jin X, Meng X et al. Phosphorus transformations at the sediment-water interface in shallow freshwater ecosystems caused by decomposition of plant debris. Chemosphere, 2018, 201: 328-334. DOI: 10.1016/j. chemosphere.2018. 03.006 .

[174] Dadi T, Wendt-Potthoff K, Koschorreck M. Sediment resuspension effects on dissolved organic carbon fluxes and microbial metabolic potentials in reservoirs. Aquatic Sciences, 2017, 79(3) : 749-764. DOI: 10.1007/s00027-017-0533-4.

[175] He Y, Men B, Yang XF et al. Relationship between heavy metals and dissolved organic matter released from sediment by bioturbation/bioirrigation. Journal of Environmental Sciences, 2019, 75: 216-223. DOI : 10.1016/j.jes.2018.03.031.

[176] Fernandez LA, Lao WJ, Maruya KA et al. Calculating the diffusive flux of persistent organic pollutants between sediments and the water column on the Palos Verdes shelf superfund site using polymeric passive samplers. Environmental Science \& Technology, 2014, 48(7) : 3925-3934. DOI: 10.1021/es404475c.

[177] Peng SC, Huang YL, Zhu SG et al. Vertical distributions and sediment-water diffusion fluxes of polycyclic aromatic hydrocarbons (PAHs) in Chaohu Lake using an in situ passive sampler. Acta Scientiae Circumstantiae, 2019, 39(2) : 491-498. DOI : 10.13671/j.hjkxxb.2018.0351. [彭书传, 黄亚龙, 朱曙光等. 基于原位被动采样技术研究巢湖沉积物和水体 中 PAHs 的垂直分布及其界面交换. 环境科学学报, 2019, 39(2) : 491-498.]

[178] Cheng HM, Hua ZL. Effects of hydrodynamic disturbances and resuspension characteristics on the release of tetrabromobisphenol A from sediment. Environmental Pollution, 2016, 219: 785-793. DOI: 10.1016/j.envpol.2016.07.055.

[179] Dong JW, Xia XH, Wang MH et al. Effect of recurrent sediment resuspension-deposition events on bioavailability of polycyclic aromatic hydrocarbons in aquatic environments. Journal of Hydrology, 2016, 540: 934-946. DOI: 10.1016/j. jhydrol.2016.07.009.

[180] Zhang YW, Wang L, Sun HW et al. Impacts of loach bioturbation on the selective bioaccumulation of HBCDD diastereoisomers and enantiomers by mirror carp in a microcosm. Chemosphere, 2016, 163: 471-479. DOI: 10.1016/j.chemosphere. 2016.08.065.

[181] Schauser I, Hupfer M, Brüggemann R. SPIEL - a model for phosphorus diagenesis and its application to lake restoration. 
Ecological Modelling, 2004, 176(3/4) : 389-407. DOI: 10.1016/j.ecolmodel.2003.10.033.

[182] Torres E, Couture RM, Shafei B et al. Reactive transport modeling of early diagenesis in a reservoir lake affected by acid mine drainage: Trace metals, lake overturn, benthic fluxes and remediation. Chemical Geology, 2015, 419: 75-91. DOI: 10.1016/j.chemgeo.2015.10.023.

[183] Doan PTK, Watson SB, Markovic S et al. Phosphorus retention and internal loading in the Bay of Quinte, Lake Ontario, using diagenetic modelling. Science of the Total Environment, 2018, 636: 39-51. DOI: 10.1016/j.scitotenv.2018.04.252.

[184] Wu Z, Liu Y, Liang ZY et al. Internal cycling, not external loading, decides the nutrient limitation in eutrophic lake: A dynamic model with temporal Bayesian hierarchical inference. Water Research, 2017, 116: 231-240. DOI: 10.1016/j. watres.2017.03.039.

[185] Shen QS, Fan CX, Wang ZD et al. Effects of $\mathrm{Fe}^{2+}$ and $\Sigma \mathrm{S}^{2-}$ transportation at sediment-water interface to the black bloom formation. J Lake Sci , 2016, 28(6) : 1175-1184. DOI: 10.18307/2016.0603. [申秋实, 范成新, 王兆德等. 湖泛水体 沉积物一水界面 $\mathrm{Fe}^{2+} / \mathrm{S}^{2-}$ 迁移特征及其意义. 湖泊科学, 2016, 28(6) : 1175-1184.]

[186] Fan CX. Progress and prospect in formation of black bloom in Lake Taihu: A review. J Lake Sci, 2015, 27(4) : 553-566. DOI: 10.18307/2015.0401. [范成新. 太湖湖泛形成研究进展与展望. 湖泊科学, 2015, 27(4) : 553-566.]

[187] Berner RA, Early D eds. A theoretical approach. Princeton: Princeton University Press, 1980: 241.

[188] Wang JN, Zhao L, Fan RF et al. Scaling relationships for diffusive boundary layer thickness and diffusive flux based on in situ measurements in coastal seas. Progress in Oceanography, 2016, 144: 1-14. DOI : 10.1016/j.pocean.2016.03.001.

[189] Zabel M, Dahmke A, Schulz HD. Regional distribution of diffusive phosphate and silicate fluxes through the sediment-water interface: the eastern South Atlantic. Deep Sea Research Part I: Oceanographic Research Papers, 1998, 45(2/3) : 277300. DOI: 10.1016/S0967-0637(97)00073-3.

[190] Zhang L, Zhu GW, Luo LC et al. Change of phosphorus load in Meiliang Bay of Taihu Lake under wind and waves and its relationship with redox characteristics. Science in China Series D: Earth Sciences, 2005, 35(S2): 138-144. [张路, 朱广 伟, 罗潋葱等. 风浪作用下太湖梅梁湾水体磷负荷变化及与水体氧化还原特征关系. 中国科学: D 辑: 地球科学, $2005,35($ S2 ) : 138-144. ]

[191] Portielje R, Lijklema L. Estimation of sediment-water exchange of solutes in Lake Veluwe, the Netherlands. Water Research, 1999, 33(1) : 279-285. DOI: 10.1016/s0043-1354(98)00202-4.

[192] Koelmans AA, Hubert E, Koopman HW et al. Modeling the vertical distribution of carbendazim in sediments. Environmental Toxicology and Chemistry, 2009, 19(4) : 793-800. DOI: 10.1002/etc.5620190403.

[193] Kasih GAA, Chiba S, Yamagata Y et al. Modeling early diagenesis of sediment in Ago Bay, Japan. Ecological Modelling, 2008, 215(1/2/3) : 40-54. DOI: 10.1016/j.ecolmodel.2008.02.025.

[194] Cheng PD, Zhu HW, Fan JY et al. Numerical research for contaminant release from un-suspended bottom sediment under different hydrodynamic conditions. Journal of Hydrodynamics, 2013, 25(4) : 620-627. DOI: 10.1016/s1001-6058(11) 60404-7.

[195] Ordoñez C, de la Fuente A, Díaz-Palma P. Modeling the influence of benthic primary production on oxygen transport through the water-sediment interface. Ecological Modelling, 2015, 311: 1-10. DOI: 10.1016/j.ecolmodel.2015.05.007.

[196] Voermans JJ, Ghisalberti M, Ivey GN. A model for mass transport across the sediment-water interface. Water Resources Research, 2018, 54(4) : 2799-2812. DOI: 10.1002/2017wr022418.

[197] Katsev S, Rancourt DG, L' Heureux I. DSED : a database tool for modeling sediment early diagenesis. Computers \& Geosciences, 2004, 30(9/10) : 959-967. DOI: 10.1016/j.cageo.2004.06.005.

[198] Wang YF, van Cappellen P. A multicomponent reactive transport model of early diagenesis : Application to redox cycling in coastal marine sediments. Geochimica et Cosmochimica Acta, 1996, 60(16) : 2993-3014. DOI: 10.1016/0016-7037(96) 00140-8.

[199] Wang SR, Jin XC, Zhao HC et al. Phosphorus release characteristics of different trophic lake sediments under simulative disturbing conditions. Journal of Hazardous Materials, 2009, 161 (2/3) : 1551-1559. DOI: 10. 1016/j. jhazmat. 2008. 05.004 .

[200] Soetaert K, Middelburg JJ. Modeling eutrophication and oligotrophication of shallow-water marine systems: the importance of sediments under stratified and well-mixed conditions. Hydrobiologia, 2009, 629(1) : 239-254. DOI : 10.1007/s10750009-9777-x. 
[201] Testa JM, Brady DC, di Toro DM et al. Sediment flux modeling: Simulating nitrogen, phosphorus, and silica cycles. Estuarine, Coastal and Shelf Science, 2013, 131: 245-263. DOI: 10.1016/j.ecss.2013.06.014.

[202] Huang SJ, Zhao HZ, Fang MP. Sediment-water exchange capacity of total phosphorus in Taihu Lake calculated by mass budget model. Environmental Science, 1992, 13(1) : 83-84, 97. [黄绍基, 赵海洲, 方满萍. 质量衡算模型计算太湖 底泥磷的交换量. 环境科学, $1992, \mathbf{1 3}(1): 83-84,97$.

[203] Wang JF , Chen JA, Luo J et al. Comparative study on quantitative estimations of phosphorus release flux from sediments of lake hongfeng, Guizhou province, China. Earth and Environment, 2018, 46(1) : 1-6. [王敬富, 陈敬安, 罗婧等. 红枫 湖沉积物内源磷释放通量估算方法的对比研究. 地球与环境, 2018, 46(1) : 1-6.]

[204] Austin ER, Lee GF. Nitrogen release from lake sediments. J Wat Pollut Control Fed, 1973 , 45(5) : 870-879.

[205] Boers PCM, van Hese O. Phosphorus release from the peaty sediments of the Loosdrecht Lakes (The Netherlands). Water Research, 1988, 22(3) : 355-363. DOI: 10.1016/s0043-1354( 88) 90240-0.

[206] Fan CX, Zhang L, Qin BQ et al. Migration mechanism of biogenic elements and their quantification on the sediment-water interface of lake Taihu: I . Spatial variation of the ammonium release rates and its source and sink fluxes. J Lake Sci, 2004, 16(1) : 10-20. DOI: 10.18307/2004.0102. [范成新, 张路, 秦伯强等. 太湖沉积物-水界面生源要素迁移机制 及定量化一1. 铵态氮释放速率的空间差异及源-汇通量. 湖泊科学, 2004, 16(1) : 10-20.]

[207] Wang ZQ, Li B, Liang RJ et al. Comparative study on endogenous release of nitrogen and phosphorus in Nansi Lake, China. Acta Scientiae Circumstantiae, 2013, 33(2) : 487-493. DOI: 10.13671/j.hjkxxb.2013.02.040. [王志齐, 李宝, 梁 仁君等. 南四湖内源氮磷释放的对比研究. 环境科学学报, 2013, 33(2) : 487-493.]

[208] Markert BE, Tesmer MG, Parker PE. An in situ sediment oxygen demand sampler. Water Research, 1983, 17(6) : 603605. DOI: $10.1016 / 0043-1354$ ( 83 ) 90227-0.

[209] McDuff RE, Ellis RA. Determining diffusion coefficients in marine sediments: A laboratory study of the validity of resistivity techniques. American Journal of Science, 1979, 279(6) : 666-675. DOI: 10.2475/ajs.279.6.666.

[210] Hong QQ, Shi XM, Wei L et al. Progresses and outlooks of the research on solute exchange across the sediment-water interface using A novel ${ }^{224} \mathrm{Ra} /{ }^{228} \mathrm{Th}$ disequilibrium approach. Bulletin of Mineralogy Petrology and Geochemistry, 2018, 37 (5) : 827-840. [洪清泉, 史向明, 魏琳等. 沉积物-水界面交换研究的天然放射性同位素 ${ }^{224} \mathrm{Ra} /{ }^{228} \mathrm{Th}$ 新体系. 矿物 岩石地球化学通报, 2018, 37(5): 827-840.]

[211] Doan PTK, Watson SB, Markovic S et al. Phosphorus retention and internal loading in the Bay of Quinte, Lake Ontario, using diagenetic modelling. Science of the Total Environment, 2018, 636: 39-51. DOI: 10.1016/j.scitotenv.2018.04.252.

[212] Guo JH, Cao Y, Zheng SJ. Numerical research on the mechanism of contaminant release through the porous sediment-overlying water interface. Journal of Hydrodynamics, 2014, 26(6) : 971-979. DOI: 10.1016/s1001-6058(14)60107-4.

[213] Smith JT, Comans RNJ, Ireland DG et al. Experimental and in situ study of radiocaesium transfer across the sediment-water interface and mobility in lake sediments. Applied Geochemistry, 2000, 15(6) : 833-848. DOI: 10.1016/s0883-2927 (99) 00095-5.

[214] Cai PH, Shi XM, Moore WS et al. ${ }^{224}$ Ra: ${ }^{228}$ Th disequilibrium in coastal sediments: Implications for solute transfer across the sediment-water interface. Geochimica et Cosmochimica Acta, 2014, 125: 68-84. DOI: 10.1016/j.gca.2013.09.029.

[215] Shi XM, Wei L, Hong QQ et al. Large benthic fluxes of dissolved iron in China coastal seas revealed by ${ }^{224} \mathrm{Ra} /{ }^{228} \mathrm{Th}$ disequilibria. Geochimica et Cosmochimica Acta, 2019, 260: 49-61. DOI: 10.1016/j.gca.2019.06.026.

[216] Bozau E, Bechstedt T, Friese $\mathrm{K}$ et al. Biotechnological remediation of an acidic pit lake: Modelling the basic processes in a mesocosm experiment. Journal of Geochemical Exploration, 2007, 92(2/3) : 212-221. DOI: 10.1016/j. gexplo. 2006. 08.007 .

[217] Ding S, Han C, Wang YP et al. In situ, high-resolution imaging of labile phosphorus in sediments of a large eutrophic lake. Water Research, 2015, 74: 100-109.

[218] Sun H, Gao B, Gao L, Using diffusive gradients in thin films (DGT) and DGT-induced fluxes in sediments model to assess the dynamic release of copper in sediment cores from the Three Gorges Reservoir, China. Science of the Total Environment, 2019, 672: 192-200.

[219] Zhu GW. Direct evidence of phosphorus outbreak release from sediment to overlying water in a large shallow lake caused by strong wind wave disturbance. Chinese Science Bulletin, 2005, 50(6) : 577-582. DOI : 10.1360/04wd0083.

[220] Wu TF, Qin BQ, Zhu GW et al. Flume simulation of wave-induced release of internal dissolved nitrogen in Taihu Lake, 
China. Chinese Journal of Oceanology and Limnology, 2012, 30(5) : 796-805. DOI : 10.1007/s00343-012-1207-7.

[221] Precht E, Huettel M. Rapid wave-driven advective pore water exchange in a permeable coastal sediment. Journal of Sea Research, 2004, 51(2): 93-107. DOI: 10.1016/j.seares.2003.07.003.

[222] Xie LQ, Xie P, Li SX et al. The low TN: TP ratio, a cause or a result of Microcystis blooms? Water Research, 2003,37 (9) : 2073-2080. DOI: 10.1016/s0043-1354(02)00532-8.

[223] Gargas E. “Sun-shade” adaptation in microbenthic algae from the Øresund. Ophelia, 1971, 9(1): 107-112. DOI: 10. 1080/00785326.1971.10430091.

[224] Wang YR, Chen XC, Chen BF et al. The release of pollutants in sediment-water interface after algal-debris accumulated in sediments. Acta Scientiae Circumstantiae, 2018, 38(1) : 142-153. DOI: 10.13671/j.hjkxxb.2017.0279. [王亚荵, 陈向 超, 陈丙法等. 藻屑堆积对沉积物-水界面污染物的释放效应. 环境科学学报, 2018, 38(1) : 142-153. ]

[225] Liu GF. Black spots of algae blooms effects on biogenic elements cycling in interface of sediment-water of Lake Taihu and its pre-control measures research [Dissertation]. Nanjing: Nanjing Institute of Geography and Limnology, Chinese Academy of Sciences, 2009: 43-53. [刘国锋. 藻源性湖泛对太湖沉积物一水界面物质行为影响及预控研究 [ 学位论文]. 南京: 中国科学院南京地理与湖泊研究所, 2009: 43-53.]

[226] Cai P, Wu YC, Liu X et al. The contribution of sediment and algal to the formation of black bloom and their potential to supply the black substance in waters in Lake Taihu. J Lake Sci, 2015, 27(4) : 575-582. DOI: 10.18307/2015.0403. [蔡 萍, 吴雨琛, 刘新等. 底泥和藻体对太湖湖泛的诱发及水体致黑物的供应潜力. 湖泊科学, 2015, 27 (4): 575-582.]

[227] Zhang YX, Xiang XP, Zhang Y et al. Distribution and sources of arsenic in Yangzonghai Lake, China. Environmental Science, 2012, 33(11) : 3768-3777. DOI: 10.13227/j.hjkx.2012.11.025. [张玉胥, 向小平, 张英等. 云南阳宗海砷的 分布与来源. 环境科学, $2012, \mathbf{3 3}(11): 3768-3777$. ]

[228] Zheng MX, Feng L, He JN et al. Delayed geochemical hazard: A tool for risk assessment of heavy metal polluted sites and case study. Journal of Hazardous Materials, 2015, 287: 197-206. DOI: 10.1016/j.jhazmat.2015.01.060.

[229] Koval PV, Kalmychkov GV, Gelety VF et al. Correlation of natural and technogenic mercury sources in the Baikal polygon, Russia. Journal of Geochemical Exploration, 1999, 66(1/2) : 277-289. DOI: 10.1016/s0375-6742(99)00041-2.

[230] Banks JL, Ross DJ, Keough MJ et al. Measuring hypoxia induced metal release from highly contaminated estuarine sediments during a 40day laboratory incubation experiment. Science of the Total Environment, 2012, 420 : 229-237. DOI: 10. 1016/j. scitotenv.2012.01.033.

[231] Roussiez V, Ludwig W, Radakovitch O et al. Fate of metals in coastal sediments of a Mediterranean flood-dominated system: An approach based on total and labile fractions. Estuarine, Coastal and Shelf Science, 2011, 92(3) : 486-495. DOI: 10.1016/j.ecss.2011.02.009. 